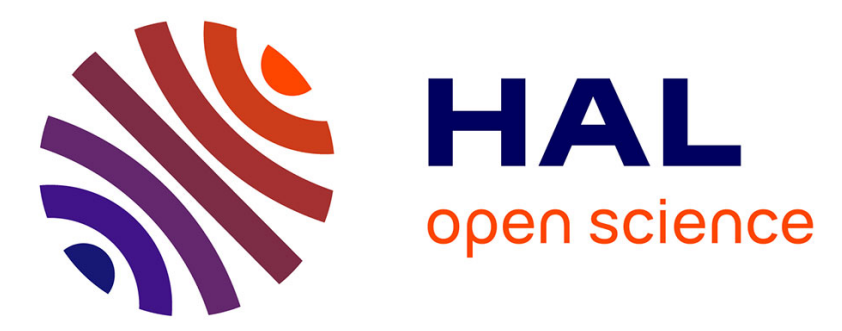

\title{
Electrochemically induced free solvent transfer in thin poly(3,4-ethylenedioxythiophene) films
}

Jéronimo Agrisuelas, Claude Gabrielli, J.J. García-Jareño, Hubert Perrot, Ozlem Sel, F. Vicente

\section{- To cite this version:}

Jéronimo Agrisuelas, Claude Gabrielli, J.J. García-Jareño, Hubert Perrot, Ozlem Sel, et al.. Electrochemically induced free solvent transfer in thin poly(3,4-ethylenedioxythiophene) films. Electrochimica Acta, 2015, 164, pp.21-30. 10.1016/j.electacta.2015.02.133 . hal-01138530

\section{HAL Id: hal-01138530 \\ https://hal.science/hal-01138530}

Submitted on 2 Apr 2015

HAL is a multi-disciplinary open access archive for the deposit and dissemination of scientific research documents, whether they are published or not. The documents may come from teaching and research institutions in France or abroad, or from public or private research centers.
L'archive ouverte pluridisciplinaire HAL, est destinée au dépôt et à la diffusion de documents scientifiques de niveau recherche, publiés ou non, émanant des établissements d'enseignement et de recherche français ou étrangers, des laboratoires publics ou privés. 
Electrochemically induced free solvent transfer in thin poly(3,4ethylenedioxythiophene) films

J. Agrisuelas ${ }^{* 1}$, C. Gabrielli ${ }^{2,3}$, J. J. García-Jareño ${ }^{1}$, H. Perrot ${ }^{2,3}$, O. Sel $^{2,3}$ and F. Vicente $^{1}$

${ }^{1}$ Departament de Química Física, Universitat de València. C/ Dr. Moliner, 50, 46100, Burjassot, València, Spain.

2 Sorbonne Universités, UPMC Univ Paris 06, UMR 8235, Laboratoire Interfaces et Systèmes Electrochimiques, F-75005, Paris, France.

${ }^{3}$ CNRS, UMR 8235, LISE, F-75005, Paris, France.

*E-mail: jeronimo.agrisuelas@uv.es 


\begin{abstract}
In dynamic intrinsically conducting films, counterions transfer and conformational movements stimulated by the electrochemical reactions affect the free water molecules transfer. Poly(3,4-ethylenedioxythiophene) or PEDOT is included in this category. Here, p-doping of PEDOT immersed in $\mathrm{LiClO}_{4}$ aqueous solution was explored by ac-electrogravimetry. Electrochemical impedance spectroscopy combined with mass impedance spectroscopy proves useful for species identification and kinetics. For PEDOT, new equations have been developed to analyze the ac-electrogravimetry response. Quantitatively, faster free water transfer and slower coupled $\mathrm{ClO}_{4}^{-} /$free water transfer were separated. Free water transfer plays a key role as a "fingerprint" of conformational movements. This might respond to fundamental questions about the mechanism of PEDOT as well as their implication in technological devices based on this polymer.
\end{abstract}

Keywords: Poly(3,4-ethylenedioxythiophene); Electrochemical quartz crystal microbalance; Electrochemical impedance spectroscopy; ac-Electrogravimetry; Electrochemically induced conformational changes. 


\section{Introduction}

Since discovery of Poly (ethylenedioxythiophene) or PEDOT, scientific community undertakes several work to prove that this material is historically one of the most successful conducting polymers[1,2]. The reversible doping state, excellent stability, regular structure without cross-linking, low band-gap, and electrochemical properties of PEDOT [3] allow this conducting polymer to be used in promising practical applications like sensors[4], anti-static coatings[5], light-emitting devices[6], solar cells[7], supercapacitors[8], actuators [9] and even as a biological tissue interfacing agent[10].

Morphology and electrochemical properties of conducting polymers like PEDOT depend strongly on the experimental conditions of polymerization[11,12]. In PEDOT films, the role of incorporated free solvent molecules (not structural) during the electrochemical reaction of synthetized polymers is as important as the transfer of ions for charge balance[13]. Free solvent stored by films lubricates the intermolecular movement acting as a plasticizer. On the contrary, film dehydration leads to stiffness of material[14,15] or increase of conductivity[16].

Mainly, the reversible transfer of anions and solvent between solution and polymer takes place during electrochemical reactions of PEDOT[17,18]. Free-volume inside the film fixes the number of free non-charged molecules, which can be inserted by the films [19]. Simplistically, rigid film oxidation involves anion insertion for charge balancing (p-doping) in this kind of polymers. At the same time, anions exclude free solvent molecules. During film reduction, free solvent occupies rapidly the free space left by anions (undoping). This fact is the so-called anion exclusion effect. In a more realistic view, redox reactions in conducting polymers often involve macromolecular rearrangements of polymer by creation and destruction of double bonds and by the accommodation of the anions. These conformational movements affect the free volume inside the film, which is occupied by free solvent molecules. Thus, doping state of the film and molecular reconfigurations during the electrochemical reactions control the free-volume[20-23].

Hillman et al. and Bund et al. have specifically explored the ion and solvent transfer in PEDOT films by cyclic electrogravimetric methods[17,18,22,23]. However, the temporal sequence in the transfer of the species and the corresponding mechanisms 
are not fully explored[24,25]. These processes are kinetically inseparable on the timescales accessed by slow transient electrochemical techniques. Electrochemical impedance analysis proves useful to separate temporally different ions/charge transfer, however, this technique is blind for non-charged species transfer[26]. Combining electrochemical and mass impedance spectroscopy, $a c$-electrogravimetry, allows an objective separation between ions/charge and solvent transfer[27-29].

The aim of this work is to go beyond of the previous electrogravimetric investigations exploiting the $a c$-electrogravimetry. This technique may separate the dynamic processes (anion transfer and free water transfer) that occur during the redox reactions of thin PEDOT films. Moreover, the study of free solvent transfer can extend the level of detail of the electrochemically induced conformational changes in PEDOT films.

Recently, a refined analytical procedure was proposed to study the anion pdoping of intrinsically conducting polymers (ICPs) by ac-electrogravimetry[30]. Here, the theory section is limited to present basic mathematical developments. The anion exclusion effect is constantly assumed in the analytical equations used to interpret the results. Thus, if the coupled anion/free water electrogravimetric response is removed from the experimental data, the remaining electrogravimetric response is because of the free water transfer stimulated by the conformational changes of the films. The kinetics transfer of this free solvent acts as a "fingerprint".

In addition to the ac-electrogravimetry study, cyclic voltammetry (CV) coupled with the Electrochemical Quartz Crystal Microbalance (EQCM) were exploited to estimate the solvent transfer during PEDOT film electrogeneration in acetonitrile/ $\mathrm{LiClO}_{4}$ solution and during the redox reaction of PEDOT film in aqueous $\mathrm{LiClO}_{4}$ solution.

Conformational changes have a key role in applications as actuators and few studies have directly addressed the kinetics of conformational changes in electroactive polymers[31,32]. Therefore, the results presented here may have marked importance for several technological applications involving PEDOT as functional coatings in contact with a liquid phase.

\section{Ac-electrogravimetry theory}

In aqueous solution, during the redox reaction of a p-type conducting polymer (P), monovalent anion, $\mathbf{A}^{-}$, transfer, which compensates the excess or defect of charge 
inside the film, can govern the opposite transfer of water molecules (exclusion effect in Figure 1). Assuming a rigid polymer, the number of water molecules, $n$, replaced by the anion insertion depends on anion volume, $V_{\mathrm{A}^{*}}$, therefore, ${ }_{\mathrm{A}^{*}}=n V_{\mathrm{M}_{2}} \mathrm{O}$.

As it was demonstrated earlier[33,34], species kinetics in thin films depend on their resistance to cross the polymer|solution interface:

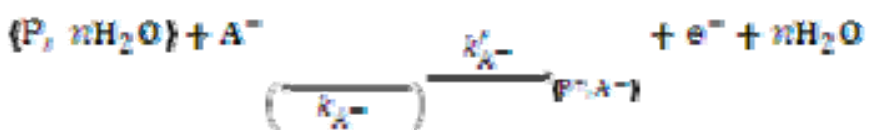

where $\left(\mathrm{P}_{2} n \mathrm{H}_{2} \mathrm{O}\right\rangle$ is the hydrated polymer and $\left\langle\mathrm{F}^{*} \mathrm{~A}^{-} \boldsymbol{V}\right.$ is the doped polymer matrix. The $k_{\mathrm{A}}$ - parameter is the kinetic constant of anion expulsion from polymer and $k_{A}^{*}$ - is the kinetic constant of anion insertion to polymer from solution.

Changes of anion concentration, $\Delta C_{A^{-}}$, during the small sine wave potential perturbation, $\triangle E$, can be defined as a function of perturbation frequency, $f,[35]$ :

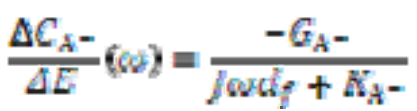

where $d_{f}$ is the thickness of the polymer film, $\omega$ is the angular frequency $(2 \pi f)$, $y=\sqrt{-1}$

$K_{A^{-}}=k_{A^{-}}+k_{A^{-}}^{\alpha}-C_{A^{-1}}^{g g^{k}}$

and

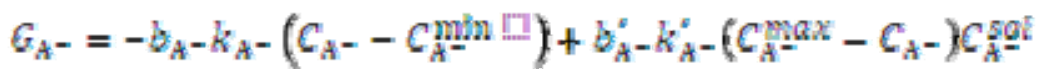

where, $C_{A^{-}}^{\max }$ is the maximum concentration of the sites for $\mathrm{A}^{-}$insertion, $C_{A^{-}}^{\min }$ is the minimum concentration of the occupied sites and $C_{\mathrm{H}^{-}}$is $\mathrm{A}^{-}$concentration in solution. $k_{A^{-}}$is $k_{A-00} \exp \left(b_{A}-\left(E-E^{0}\right)\right)$ and $k_{A^{-}}^{\prime}=k_{A-00} \exp \left(b_{A^{\prime}}^{\prime}\left(E-E^{0^{\prime}}\right)\right)$ where $E^{Q^{\prime}}$ is the formal potential and $k_{\mathrm{A}-0_{0}}$ is a preexponential factor of the kinetic rate constants independent of applied potential $E$.

The parameters, $b_{A^{-}}$and $b_{A^{-}}^{c}$ are the Tafel coefficients:

$b_{A^{-}}-b_{A^{-}}^{s}=B_{A^{-}}=\frac{n_{\mathrm{A}^{-}} F}{R T}$

where $R$ is the gas constant and $T$ is the absolute temperature. From these coefficients, one can estimate the number of electrons $\left(n_{z^{-}}\right)$involved in the faradaic process and the symmetry of direct and reverse transition on the formal redox potential[36,37].

Often, electrochemical reactions of film induce conformational changes (swelling, shrinking, compaction, or relaxation). Therefore, a constant thickness of films 
cannot be considered since it may change depending on the polarization potential[3841].

Eq (2) is slightly modified in terms of surface concentration as[28,29]:

$d_{f} \frac{\Delta C_{A^{*}}}{\Delta E}(\omega)=\frac{\Delta \Gamma_{A^{*}}}{\Delta E}(\omega)=\frac{-G_{A^{-}}}{j \omega+K_{\lambda^{-}}}$

where $K^{*}$ is $K / d /$.

Based on this model, theoretical electrochemical impedance, $\Delta E / \Delta I \omega \%$ is expressed as:

$\frac{\Delta E}{\Delta I}(\omega)=R_{\mathrm{s}}+\frac{1}{j \omega C_{d l}+j \omega \frac{\Delta q}{\Delta E}(\omega)}$

where $R_{u}$ is the uncompensated solution resistance, $\mathcal{C}_{\mathfrak{d} k}$ is the double layer capacity, ${ }^{F}$ is the Faraday constant, and $S$ is the active electrode surface area.

The electrical charge/potential transfer function, $\Delta q / \Delta E(\omega)$, is equal to:

$\frac{\Delta q}{\Delta E}(\omega)=S E\left[\frac{G_{A^{-}}}{l \omega+K_{\hbar^{-}}^{\prime}}\right]$

which is better to compare with the sinusoidal electrogravimetric response.

Considering the participation of anion and water in mass changes, the mass/potential transfer function, $\stackrel{A m}{m_{\triangle E}(\omega)}$, is:

$\frac{\Delta m}{\Delta E}(\omega)=s\left(\delta_{A}-M_{\mathrm{A}}-\left[\frac{G_{\mathrm{A}}-}{j \omega+K_{\mathrm{A}}^{e}}\right]+n \tilde{\delta}_{\mathrm{H}_{2} 0} M_{\mathrm{H}_{2} \mathrm{O}}\left[\frac{G_{\mathrm{H}_{2} \mathrm{O}}}{j \omega+K_{\mathrm{H}_{2} \mathrm{O}}^{*}}\right]\right)$

and by assuming the exclusion effect, $G_{\mathrm{A}^{-}}=G_{\mathrm{H}_{2} 0}$ and $K_{\mathrm{A}^{-}}^{\prime \prime}=K_{\mathrm{H}_{2} 0}^{\prime}$ (Figure 1). Then eq (9) is simplified to:

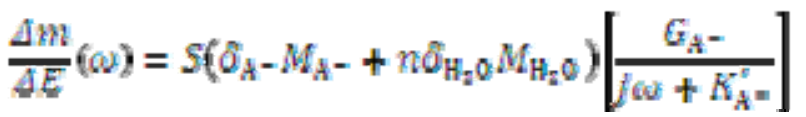

where $M_{1}$ is the molar mass of the ${ }^{i}$ species involved $\left(A^{-}\right.$or $\left.\mathbf{H}_{2} \mathrm{O}\right)$ and $K_{\mathrm{H}_{2} \mathrm{O}}^{\prime \prime}$ and $G_{\mathrm{H}_{2} \mathrm{O}}$ have a similar meaning as eq (3) and (4), respectively. $\hat{\delta}_{A^{-}}$is +1 because of $A^{-}$ insertion during oxidation, whereas, $\delta_{\mathrm{Hz}_{2} \mathrm{U}}$ is -1 because of $\mathrm{H}_{2} \mathrm{O}$ expulsion induced by anion insertion.

In dynamic films, eq (10) cannot explain the electrogravimetric response [30]. The conformational changes, which affect the transfer of free water molecules, have 
different kinetics than anion transfer. A more complete and realistic expression for $\Delta m_{/ \Delta E(\omega)}$ takes into account both kinds of free water transfers as:

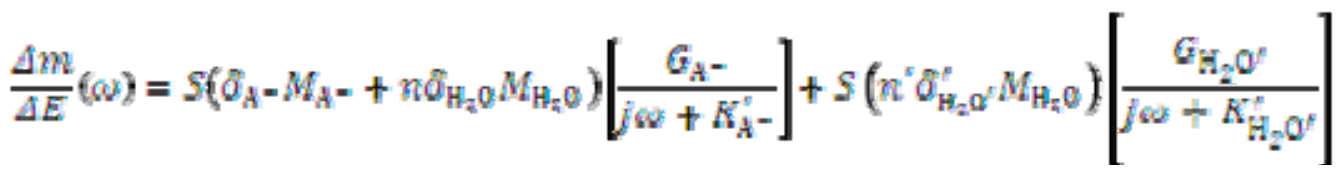

where $\tilde{H}_{\mathrm{H}_{2} \mathrm{O}^{n}}^{*}$ indicates the direction of transfer and the number of molecules of $\mathrm{H}_{2} \mathrm{O}$ associated with conformational movements $\left(n^{n}\right)$ can be equal or different than $n \cdot G_{\mathrm{H}_{2} 0^{2}}$ and $K_{\mathrm{H}_{2} \mathrm{O}^{\prime}}^{\prime}$ are kinetic parameters of free water transfer from induced conformational movements.

\section{Experimental}

\subsection{Film preparation}

The electrochemical polymer deposition and characterization were performed by cyclic voltammetry (CV) using an AUTOLAB potentiostat-galvanostat (PGSTAT302). A lab-made oscillator acted as an Electrochemical Quartz Crystal Microbalance (EQCM) at room temperature (about $295 \pm 2 \mathrm{~K}$ ). The three-electrode cell involved a reference electrode (Saturated Calomel Electrode or SCE, Tacussel XR 600) and a platinum counter electrode. The working electrode was a gold electrode $\left(S=0.3 \mathrm{~cm}^{2}\right)$ patterned on a $9 \mathrm{MHz}$ quartz crystal resonator (TEMEX, France). All the solutions were prepared with deionized and double-distilled water. The potential of the working electrode is referred to the SCE reference electrode in all measurements. PEDOT films were electrodeposited after 10 voltammetric cycles between $-0.2 \mathrm{~V}$ and $1.1 \mathrm{~V}$ at 100 $\mathrm{mV} \mathrm{s}^{-1}\left(\sim 80 \mu \mathrm{g} \mathrm{cm}^{-2}\right.$ of the deposited mass). The polymerization solution was $0.1 \mathrm{M}$ $\mathrm{LiClO}_{4}$ (Sigma-Aldrich) and 0.05 M EDOT (Aldrich) in acetonitrile (Sigma-Aldrich) solution.

\subsection{Film conditioning}

Previously to ac-electrogravimetry experiments, PEDOT film was cycled between $-0.4 \mathrm{~V}$ and $0.8 \mathrm{~V}$ at $100 \mathrm{mV} \mathrm{s}^{-1}$ in $0.1 \mathrm{M} \mathrm{LiClO}_{4}$ aqueous solution. After the first cycle, changes in the shape of the voltammetric and electrogravimetric responses are almost negligible at least within $10 \mathrm{CV}$ cycles.

\section{3. ac-Electrogravimetry}

$a c$-Electrogravimetry investigation of the PEDOT films was performed at steady state potentials in the range of $0.7 \mathrm{~V}$ to $-0.25 \mathrm{~V}$ in the same solution. The lower limit 
was agreed to avoid any significant degradation[42]. For that, a fast EQCM was coupled with a four-channel frequency response analyzer (FRA, Solartron 1254) and a potentiostat (SOTELEM-PGSTAT Z1). The modified working electrode was polarized at a given potential and a sinusoidal potential perturbation with a small amplitude (10 $\mathrm{mV} r m s$ ) was superimposed between $65 \mathrm{kHz}$ and $0.01 \mathrm{~Hz}$. The microbalance frequency change, $\Delta f_{m}$ and the alternating current response, $\Delta I$, were sent to the four channels FRA, which allowed the electrogravimetric transfer function, $\Delta m / \Delta E(\omega)$ and the electrochemical impedance, $\Delta E_{\Delta I(\omega)}$, to be simultaneously obtained. Finally, the experimental data were fitted with the theoretical expressions given in Section 2 by means of Levenberg-Marquardt method[43].

\section{Results and discussion}

Several works have tried to unfold stoichiometry and mechanisms of electrochemically induced solvent transfer in PEDOT films. Here, the solvent transfer is studied from the cyclic electrogravimetric response (EQCM) of PEDOT in acetonitrile and water solutions. The purpose of the EQCM study is not to make novel claims, but to show that PEDOT produced is a typical film of those studied elsewhere by cyclic voltammetry. However, these results are significant in the sense that they provide a first approximation to interpret $a c$-electrogravimetry results.

\subsection{Free acetonitrile transfer during p-doping}

In acetonitrile, EDOT radicalization starts when the potential applied reaches to $1 \mathrm{~V}$. The first $\mathrm{CV}$ in Figure 2 shows a rising intensity with a mass jump on electrode of about $4 \mu \mathrm{g} \mathrm{cm}^{-2}$. The mass/charge ratio is about $+150 \mathrm{~g} \mathrm{~mol}^{-1}$ between $1 \mathrm{~V}$ and $1.2 \mathrm{~V}$ in both scan directions. Considering the molar mass of monomer $\left(M_{\mathrm{EDOT}}=142 \mathrm{~g} \mathrm{~mol}^{-1}\right)$, the ratio points to one electron for one monomer radicalization. The film deposition increase monotonically after the third CV cycle (inset of Figure 2). The final mass deposited after $10 \mathrm{CV}$ cycles is about $8 \mu \mathrm{g} \mathrm{cm}$. This amount corresponds to a thickness of about $60 \mathrm{~nm}$ assuming that the monomer density is $\sim 1.3 \mathrm{~g} \mathrm{~cm}^{-3}$. This estimation had not considered the ionic and solvent species population inserted inside film during the electropolymerization. Despite this, we can assume a thin PEDOT film[19].

After few cycles, a pseudo-capacitive behavior appears between $-0.2 \mathrm{~V}$ and $1 \mathrm{~V}$ without distinct redox peaks (Figure 3a). During the oxidation reaction, positive values 
of mass derivative proves clearly the mass increase owing to insertion of $\mathrm{ClO}_{4}^{-}$(pdoping) and during the reduction reaction, negative values of mass derivative are because of $\mathrm{ClO}_{4}^{-}$dedoping.

The instantaneous mass/electrical charge ratio, $F(\mathrm{dm} / \mathrm{dq})$, has proved especially useful in the analysis of the electrochemical reactions during $\mathrm{CV}$ experiments [44]. The mechanism of free acetonitrile transfer can be evaluated with this equation. Figure $3 \mathrm{~b}$ shows $F(\mathrm{dm} / \mathrm{dq})$ at the $10^{\text {th }}$ cycle of electropolymerization. The obtained values are close to the molar mass of $\mathrm{Clo}_{4}^{-}\left({ }^{M_{\mathrm{elo}}^{-}}=99.5 \mathrm{~g} \mathrm{~mol}^{-1}\right)$. Between $0.2 \mathrm{~V}$ and $1 \mathrm{~V}, F(\mathrm{dm} / \mathrm{dq})$ reaches values close to $+150 \mathrm{~g} \mathrm{~mol}^{-1}$ corresponding to the transfer of one $\mathrm{ClO}_{4}^{-}$together a one acetonitrile molecule $\left({ }_{\mathrm{CH}_{2} \mathrm{CN}}=41 \mathrm{~g} \mathrm{~mol}^{-1}\right)$ between the film and solution by electron transfer. On the contrary, $F\left({ }^{d m} /{ }_{d q}\right)$ is close to $+70 \mathrm{~g} \mathrm{~mol}^{-1}$ between $-0.2 \mathrm{~V}$ and $0.2 \mathrm{~V}$. This value corresponds to the theoretical values of the transfer of one $\mathrm{ClO}_{4}^{-}$with the opposite transfer of one acetonitrile molecule by electron transfer. Under these experimental conditions, $\mathrm{Li}^{+}$is not involved in the charge balance[17].

In acetonitrile, PEDOT film shows a compact structure owing to PEDOTsolvent interactions[45]. However, molecular reconfiguration is assumed in the electrochemical mechanisms of conducting polymers[46]. An approximation to polymer conformational movements consists of solving the stoichiometric relation between the doping molecules, in this case $\mathrm{ClO}_{4}^{-}$, and the solvent transfer[28,29]. By using the commercial software ChemBio3D Ultra v. 12.0 ChemBioOffice 2010, the volume of $\mathrm{ClO}_{4}^{-}\left({ }^{V} \mathrm{ClO}_{4}^{-}\right)$and acetonitrile $\left({ }^{V} \mathrm{CH}_{2} \mathrm{CN}\right)$ is calculated from the Connolly solventexcluded volume. Considering $V_{\mathrm{ClO}_{4}^{-}}=47 \mathrm{~A}^{\mathrm{a}}$ and $V_{\mathrm{CH}_{2} \mathrm{Cx}}=37 \mathrm{~A}^{3}$, one $\mathrm{ClO}_{4}^{-}$can replace approximately one acetonitrile molecule as a result of an exclusion effect. This fact is observed in the potential range between $-0.2 \mathrm{~V}$ to $0.2 \mathrm{~V}$ when doping level of PEDOT film is lower. In this potential range, PEDOT could not be completely relaxed and acts as a rigid film. However, the molecular arrangements of a relaxed and doped PEDOT film allow the coupled insertion of $\mathrm{ClO}_{4}^{-}$and $\mathrm{CH}_{3} \mathrm{CN}$ between $0.2 \mathrm{~V}$ and $1 \mathrm{~V}$. 


\subsection{Free water transfer during $p$-doping}

In water solution (Figure 4a), PEDOT film generated in acetonitrile preserves the capacitor-like shape, and displays not well defined redox peaks with a formal potential around $0 \mathrm{~V}[14,47]$. However, the electrogravimetric response proves different. It is expected that the exchange of large solvent molecules $\left(\mathrm{CH}_{3} \mathrm{CN}\right)$ by small solvent molecules $\left(\mathrm{H}_{2} \mathrm{O}\right)$ should improve the study of conformational changes in PEDOT films.

Like in acetonitrile, $F(\mathrm{dm} / \mathrm{dq})$ shows two different tendencies in Figure $4 \mathrm{~b}$. $F(\mathrm{dm} / \mathrm{dq})$ is lower than molar mass of $\mathrm{Clo}_{4}^{-}$between $-0.2 \mathrm{~V}$ and $0.1 \mathrm{~V}$. Thus, water transfer is in opposite direction of the anion transfer. On the contrary, $F\left({ }^{d m} / d q\right)$ is higher than ${ }^{\mathrm{ClO}_{4}^{-}}$between $0.1 \mathrm{~V}$ and $0.8 \mathrm{~V}$. Here, anion and solvent transfer by electron transfer are coupled in the same direction. Considering water volume $\left(V_{\mathrm{H}_{2} \mathrm{O}}=10 \mathrm{~A}^{3}\right), \mathrm{ClO}_{4}^{-}$can exclude about 4.7 water molecules. At $-0.2 \mathrm{~V}, \mathrm{ClO}_{4}^{-}$ insertion results in the expulsion of about 3 water molecules. The number of excluded water molecules gradually decrease to 0 at $0.1 \mathrm{~V}$. These values are far from the theoretical values. On the contrary, the number of water molecules accompanying the anion insertion goes from 0 at $0.1 \mathrm{~V}$, to close to 3 water molecules around $0.8 \mathrm{~V}$. Thus, the exclusion effect can be neglected in this potential range. As the doping level increases, the coulomb repulsion between charged sites becomes stronger, forcing the polymer to expand[48].

Like in systematically CV experiments [49], conformational changes during electrochemical reaction hinder to reach a complete understanding of the temporal sequence of redox mechanism in PEDOT films. This aspect will be elucidated by acelectrogravimetry.

\subsection{Kinetic model for PEDOT films in $\mathrm{LiClO}_{4}$ aqueous media}

In a first sight, we can distinguish up to three capacitive processes in the experimental $\triangle q / \Delta E(\omega)$ from raw electrochemical impedance. Figure 5 shows all processes at two representative potentials, namely $-0.25 \mathrm{~V}$ and $0.5 \mathrm{~V}$.

Around $10-1 \mathrm{KHz}$, a capacitive process $(C P)$ is always observed at all potentials. This process is considered as a $R_{G y}, C_{c y}$ circuit because this is not associated to the ionic transfer. So, the partial contribution of this process to $\Delta q / \Delta E(\infty)$ function is [28]: 


$$
\left[\frac{\Delta q}{\Delta E}(\omega)\right]_{c p}=\frac{1}{f \omega R_{c p}+\frac{1}{C_{c p}}}
$$

This faradaic process is faster than $\mathrm{ClO}_{4}^{-}$transfer in PEDOT film and can be the reason of the pseudo-capacitive current observed in CV experiments (Figure 4). In this time domain, the electrons from electrode may penetrate in the polymer only close to the electrode|polymer interface. Ions in solution are not sufficiently fast to cross the polymer|solution interface. PEDOT film acts as a dielectric material separating both charged planes to form a pseudo-capacitor[8,50].

At low frequencies domain, $\Delta q / \Delta E(\omega)$ shows a quasi-vertical branch at more cathodic potentials (Figure 5). This parallel reaction $(p)$ is usually observed in conducting polymers deposited on electrodes [28,51,52]. Like above, the partial contribution to $\Delta q / \triangle E(\omega)$ is fitted to a $R_{p}, C_{p}$ circuit as:

$$
\left[\frac{\Delta q}{\Delta E}(\omega)\right]_{p}=\frac{1}{f \omega R_{p}+\frac{1}{C_{p}}}
$$

In between these two frequency ranges, the partial contribution of $\Delta q / \Delta E(\omega)$ associated to $\mathrm{ClO}_{4}^{-}$transfer can be expressed using eq (8) with some modifications:

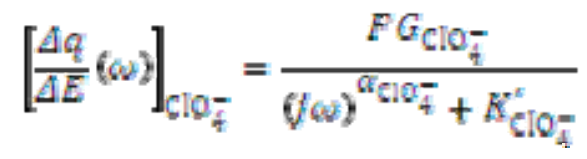

This term considers a constant phase element introduced as an exponent of $/ \omega$. Here, ${ }^{{ }^{\mathrm{c}} 10_{4}^{-}}$is a mathematical correction to achieve the best fittings because often, real samples do not fit ideal equations $\left({ }^{{ } \mathrm{ClO}_{4}^{-}}=1\right.$ ) $[53,54]$. This correction does not cause any change in the physical meaning of the kinetic parameters [28].

Accordingly, the equation used for the multiparametric fitting process was:

$$
\frac{\Delta Q Q}{\Delta E}(\omega)=\left[\frac{\Delta q}{\Delta E}(\omega)\right]_{S p}+\left[\frac{\Delta Q}{\Delta E}(\omega)\right]_{C 10^{-}}+\left[\frac{\Delta q}{\Delta E}(\omega)\right]_{p}
$$

Reasonable convergences are found using this equation as the simulations show (solid lines in Figure 5). It is important to observe ${ }^{\alpha_{\mathrm{Cl}}{ }_{4}^{-}}$values are close to ideality $(0.848 \pm 0.006)$ at all polarization potentials. This corroborates with the low thickness of the PEDOT film. In thicker films, a Warburg-like response due to the charge diffusion 
inside the film should evolve ${ }^{{ } \mathrm{ClO}_{4}^{-}}$far from unity[26]. The kinetic parameters for $\mathrm{ClO}_{4}^{-}$

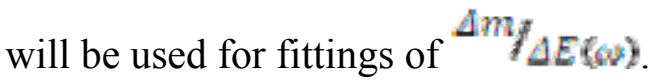

Up to here, free water transfer does not take part in the charge balance owing to the neutral character of solvent. However, water insertion and expulsion involve in the effective mass changes. Firstly, we consider an exclusion effect ( $e x$ ) by anions at all

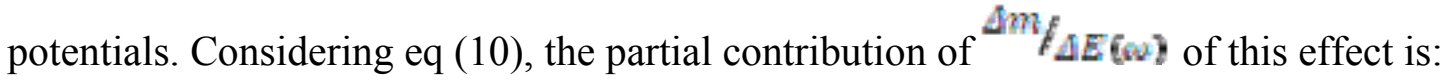

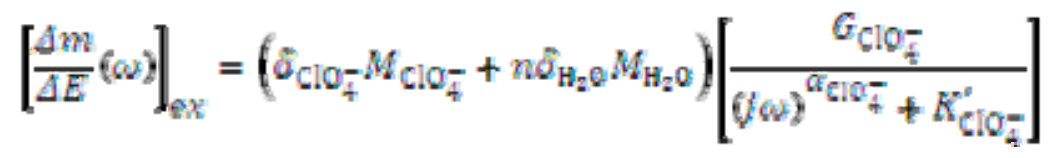

To detect/separate free water transfer out of exclusion effect, the analysis of real part of $F \Delta m / \Delta q(\infty)$ as a frequency function at different potentials can be useful (Figure 6). The results together with $\mathrm{CV}$ discussion help to propose a theoretical equation of $\Delta m / \Delta E(\omega)$ for PEDOT.

As it was expected, ${ }^{F \Delta m_{A q}(\omega)}$ shows values above and below of ${ }^{M_{\mathrm{ClO}}^{-}}$. We can organize the discussion as a function of both parameters, perturbation frequency and polarization potential. As a function of applied potential, $F \Delta m / \Delta q(\omega)$ trends are similar to those observed in $\mathrm{CV}$ experiments. At more negative potentials, $F \Delta / A q(\omega)$ is lower than ${ }^{M_{\mathrm{ClO}}^{-}}$because $\mathrm{ClO}_{4}^{-}$exclude $\mathrm{H}_{2} \mathrm{O}$ during the species transfers. On the contrary, $F \Delta m_{\Delta q(\omega)}$ reaches values above ${ }^{M_{\mathrm{ClO}_{4}^{-}}}$at more positive values. Film expansion allows the transfer of $\mathrm{ClO}_{4}^{-}$and $\mathrm{H}_{2} \mathrm{O}$ in the same direction[48].

However, ${ }^{F \Delta m} f_{\Delta q(\omega)}$ evolution on frequency provides more information. Up to $1 \mathrm{~Hz}, F \Delta m / \Delta q(\omega)$ exhibits lower values than those that appear at lower frequencies, especially at positive potentials (Figure 6). Thus, the water exclusion by anions is expected. However, the ionic transfer does not occur above $100 \mathrm{~Hz}$ because the diffusivity of ions is low. The free water transfer may be governed by a different process. PEDOT films have shown faster electrochromic switches up to a modulation frequency of $100 \mathrm{~Hz}[55]$. The faster electronic transfer between the electrode and PEDOT may lead to macromolecular conformational changes by formation and 
destruction of double bonds. Therefore, conformational changes can involve a free water transfer because water has a higher mobility than anion.

The main question is the flux direction of water molecules regarding anion transfer. By taking the results at $0.25 \mathrm{~V}$ as a reference, lower values of $F \Delta m / \Delta q(\omega)$ than $M_{\mathrm{ClO}_{4}}$ are obtained around $100 \mathrm{~Hz}$. After that, an increase of $F \Delta m / \Delta q(\omega)$ above $M_{\mathrm{ClO}_{4}^{-}}$occurs up to constant values around $125 \mathrm{~g} \mathrm{~mol}^{-1}$ in the slow perturbation domain (between 1 and $0.01 \mathrm{~Hz}$ ). Thus, fast structural movements of PEDOT involve the expulsion of $\mathrm{H}_{2} \mathrm{O}^{\prime \prime}$ (from now on, $-\mathrm{H}_{2} \mathrm{O}^{\prime}$ ) and a slower free water insertion is expected with anion insertion (from now on, $+\mathrm{H}_{2} \mathrm{O}^{4}$ ) during oxidation, opposite during reduction. The partial contribution of $\Delta m / \Delta E(\omega)$ of both free water transfers can be expressed as:

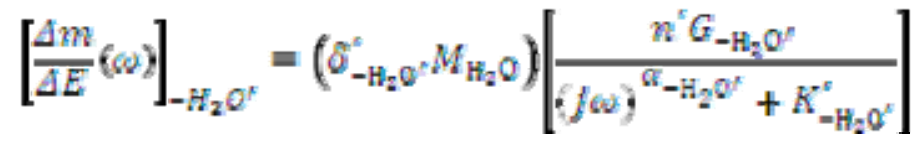

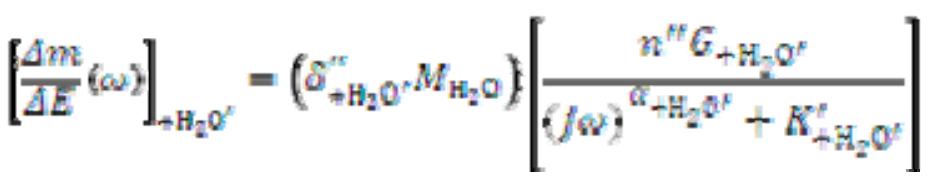

Thus, the resulting theoretical expression of $\Delta m_{A E}(\omega)$ transfer function is:

$$
\frac{\Delta m}{\Delta E}(\omega)=\left[\frac{\Delta m}{\Delta E}(\omega)\right]_{Q x}+\left[\frac{\Delta m}{\Delta E}(\omega)\right]_{-\mathrm{H}_{2} O^{\circ}}+\left[\frac{\Delta m}{\Delta E}(\omega)\right]_{-\mathrm{H}_{2} \sigma}
$$

$\delta_{i}$ where $t^{i}$ is $\mathrm{ClO}_{4}^{-}, \mathrm{H}_{2} \mathrm{O},-\mathrm{H}_{2} \mathrm{O}^{\prime}$ or ${ }^{-\mathrm{H}_{2} \mathrm{O}^{\prime}}$ is +1 for species inserted during polymer oxidation or -1 for species inserted during polymer reduction. The $n^{n}$ and $n^{r^{n}}$ parameters represent the number of water molecules transferred by electron transfer because of changes of free volume inside film driven by electrochemically induced conformational changes.

To reduce the number of free parameters for later fittings, some values are fixed in eq (19) as following:

$$
\begin{aligned}
& \text { - }\left(\delta_{\mathrm{ClO}_{4}^{-}} M_{\mathrm{ClO}_{4}^{-}}+n \hat{\delta}_{\mathrm{H}_{2} \mathrm{O}} M_{\mathrm{H}_{2} \mathrm{O}}\right) \text { can be fixed as } 1^{4.0} \mathrm{~g} \mathrm{~mol}^{-1} \text { where }{ }^{\hat{\mathrm{ClO}}_{4}^{-}}=+1 \text {, } \\
& \hat{Q}_{\mathrm{H}_{2} \mathrm{O}} M_{\mathrm{H}_{2} \mathrm{O}}=-18 \mathrm{~g} \mathrm{~mol}^{-1} \text { and } n=4.7 \text { considering } \mathscr{\mathrm { ClO }}_{\frac{-}{4}}=4.7 \mathrm{~A}^{\mathrm{z}} \text { and } \\
& V_{\mathrm{H}_{2} \mathrm{O}}=10 \mathrm{~A}^{\mathrm{a}} \text {. }
\end{aligned}
$$


$-G_{\mathrm{ClO}_{\overline{4}}^{-}}, K_{\mathrm{ClO}_{\overline{4}}^{-}}^{n}$ and ${ }^{\alpha_{\mathrm{CHO}}^{-}}$come from fittings between experimental $\Delta q / \Delta E(\omega)$ and eq (15).

- $\sigma_{-\mathrm{H}_{2} \mathrm{O}^{-}}^{E} M_{\mathrm{H}_{2} \mathrm{O}}$ is $-18 \mathrm{~g} \mathrm{~mol}^{-1}$ owing to the expulsion from film during $\mathrm{ClO}_{4}^{-}$ insertion in the oxidation.

- $\delta_{+\mathrm{H}_{2} \mathrm{O}^{\prime}}, \mathrm{M}_{\mathrm{H}_{2} \mathrm{O}}=+18 \mathrm{~g} \mathrm{~mol}^{-1}$ because $\mathrm{H}_{2} \mathrm{O}$ is inserted with $\mathrm{ClO}_{4}^{-}$during the oxidation.

Therefore, six parameters are free for fittings within physically reasonable

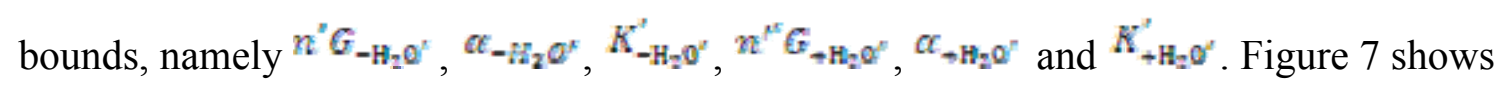
good convergences between experimental $\triangle m / \triangle A E(\omega)$ curve and eq (19). Like in

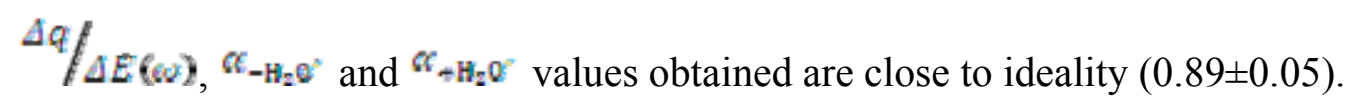

From $\mathrm{CV}$ results, the exclusion effect is neglected between $0.1 \mathrm{~V}$ and $0.8 \mathrm{~V}$. An alternative to eq (19) may include this fact. However, eq (19) was applied to all studied potentials with an excellent agreement. Later, the analysis of kinetic parameters will show if there is exclusion effect or not.

\subsection{Identification of electrochemical processes.}

The derivative of the surface insertion law for $\mathrm{ClO}_{4}^{*}$ with respect to the potential

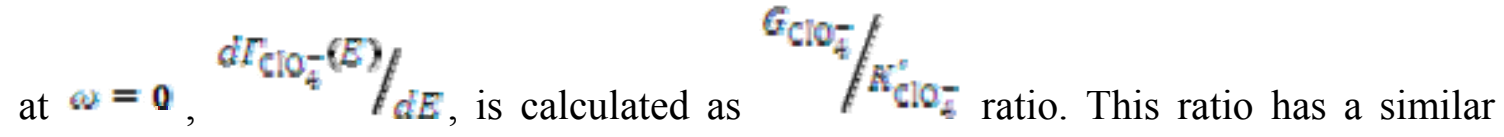
meaning as the theoretical derivation of a voltammetric peak. Therefore, the electrochemical reaction of PEDOT can be positioned on the potential scale (Figure 8).

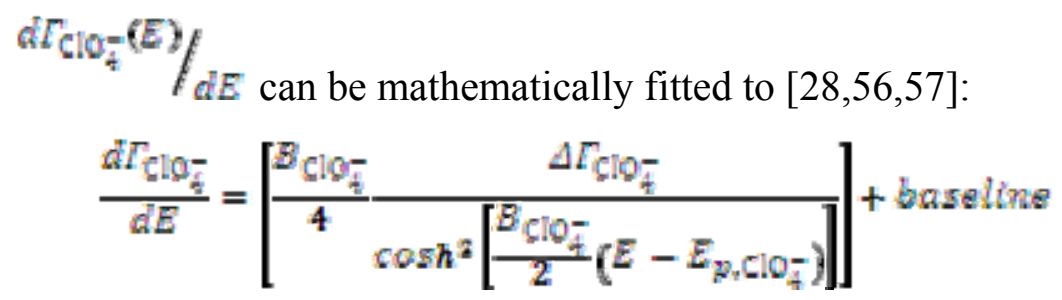

and it can be simulated using the parameters showed in the inset of Figure 8 .

Like in CV, PEDOT shows only one electrochemical process with a potential peak around $0 \mathrm{~V}$. About $5.3 \mathrm{nmol} \mathrm{cm}$ of $\mathrm{ClO}_{4}^{-}$can be inserted during the redox conversion of PEDOT. Moreover, a constant amount of $\mathrm{ClO}_{4}^{-}\left(30 \mathrm{nmol} \mathrm{cm}^{-2} \mathrm{~V}^{-1}\right)$ is transferred between film and solution independently of oxidation state. This fact agrees 
with the existence of polaronic forms even in reduced and apparently undoped states of PEDOT [58].

\subsection{Obtaining n' and n’’}

At this point, $n^{\prime} G_{-H_{2} \mathrm{O}^{\prime}}$ and $n^{n^{\prime \prime} G_{* \mathrm{H}_{2} \mathrm{O}^{\gamma}}}$ are acquired from fittings. The set of $\mathrm{H}_{2} \mathrm{O}$ transferred out of exclusion effect in the same direction $\left(n^{r^{\prime \prime}}\right)$ and in the opposite direction $\left(n^{\mathrm{t}}\right)$ by electron transfer are still unknown.

By taking into account the simplistic scheme of anion and free water transfers in Figure 1, one monovalent anion transfer involves the transfer of one set of water molecules owing to exclusion effect $\left(\mathrm{nH}_{2} \mathbf{0}\right)$. Extrapolating to PEDOT, it is possible to estimate $n^{r}$ and $n^{l^{*}}$ considering that surface concentration of $\mathrm{ClO}_{n}^{-}$is equal to surface concentration of $-\mathrm{H}_{2} \mathrm{O}^{\prime \prime}$ and $\mathrm{t}_{2} \mathrm{O}^{\prime \prime}, \Gamma_{\mathrm{ClO}_{4}^{-}}=F_{+\mathrm{H}_{2} \mathrm{O}^{*}}=F_{-\mathrm{Hg}_{\mathrm{g}} \mathrm{O}^{\prime \prime}}[28,29]$. Thus,

Table 1 shows the evolution of the number of $\mathrm{H}_{2} \mathrm{O}$ on the oxidation state of PEDOT. The number of free water molecules excluded by anion $(n)$ is assumed constant at 4.7 in the overall studied potentials. However, the transfer of water molecules in both direction $\left(-\mathrm{H}_{2} \mathrm{O}^{\prime \prime}\right.$ and $\left.+\mathrm{H}_{2} \mathrm{O}^{\prime \prime}\right)$ increases as PEDOT is oxidized owing to the swelling of PEDOT structure[48]. At potentials where PEDOT is doped, the number of water molecules transferred is about 60 . This fact indicates a wide freevolume inside PEDOT favored by two elements, acetonitrile template during the polymerization and anion inserted during the oxidation.

The net water molecules transferred calculated as $n^{\prime \prime}-n^{\prime}-n$ shows that a net insertion of $\mathrm{H}_{2} \mathrm{O}$ by anion (hydration of film) takes place from $0 \mathrm{~V}$ to positive potentials when PEDOT is predominantly doped. On the contrary, a net loss of $\mathrm{H}_{2} \mathrm{O}$ 
(dehydration of film) takes place from $0 \mathrm{~V}$ to negative potentials when PEDOT is predominantly undoped. As it was commented above, CV also shows this evolution (Figure 4).

\subsection{Ease of the species transfer at the polymer|solution interface.}

Parameter $G$ refers to the ease of species transfer to cross the polymer|solution interface [59]. As it is expected, species transfer takes place easier around the formal potential of PEDOT under these experimental conditions (Figure 9). ${ }^{G_{\mathrm{ClO}}}{ }_{+}$and ${ }^{G_{+\mathrm{H}_{2} \mathrm{O}^{*}}}$ are 2.0-2.5 $\mu \mathrm{mol} \mathrm{s} \mathrm{cm}^{-1} \mathrm{~V}^{-1}$ because both species are transferred coupled. ${ }^{G} \mathrm{H}_{2} \mathrm{O}^{5}$ shows values slightly higher indicating an easier transfer of free water in the opposite direction of anions.

$G$ has exponential dependence at potentials far from the peak potential as[60]:

$$
G_{i}=\frac{G_{i}^{\max }}{\cosh \left[\frac{B_{i}}{2}\left(E-E_{p, i}\right)\right]}
$$

where $i$ is $\mathrm{ClO}_{4}^{-},-\mathrm{H}_{2} \mathbf{0}^{*}$ or $+\mathrm{H}_{2} \mathbf{a}^{*}, G_{2}^{\max }$ represents the maximum value for this function at $E=E_{p, i}$, and $E_{p, i}$ represent the peak potential of $G_{i}$.

By considering eq (5), for the oxidation half-reaction:

$$
\frac{B_{i}}{2}=\frac{n_{\mathrm{e}}-\alpha F}{R T}
$$

and for the reduction half-reaction:

$$
\frac{B_{i}}{2}=\frac{n_{\mathrm{i}}-(1-\omega) E^{*}}{R T}
$$

Values of $\alpha=0.5$ imply the variation of $G_{i}$ on the applied potential presents a symmetry on the peak potential, and values for $B_{i}$ are the same for direct and reverse reaction. In any other case, $B_{i}$ values are different, and the dependence of $G_{i}$ on the applied potential should be asymmetric.

At $298 \mathrm{~K},{ }^{B_{t} / z_{2}}=19.5 \mathrm{~V}^{-1}$ for $m_{z^{-}}=1$ and $\alpha=0.5$ since one electrochemical reaction occurs. From the slope of $\log \left(G_{\mathrm{H}_{2} \mathrm{O}^{2}}\right)$ versus $E$ plot, values around $3 \mathrm{~V}^{-1}$ are determined, which are close to that obtained in Figure $8\left(6 \mathrm{~V}^{-1}\right)$. Lateral interactions between randomly distributed electroactive sites lessen the theoretical value of $B_{i}$ considering the Laviron model based on the Frumkin-type isotherm[29]. These low values point to a very intensive lateral interaction between charged sites of PEDOT. 


\subsection{Rate of species transfer at the polymer|solution interface.}

As it was expounded above, $K^{*}$ provides the transfer rate of species, eq (3). Figure 10 shows the evolution of $K^{r}$ on the potential. The exclusion effect $\left({ }^{\mathrm{Clo}_{\mathbb{L}}^{-}}\right)$and the insertion of water molecules out of exclusion effect $\left({ }^{K_{\rightarrow}^{\prime}} \mathrm{H}_{2} \mathrm{O}^{\prime \prime}\right)$ have quasi-identical values about 60-65 $\mathrm{s}^{-1}$. Moreover, the rates decrease as the polymer becomes undoped and, possibly, becomes more compact. Although mathematically can be separated, the results point out to coupled transitions. Unlike CV, anion exclusion can be neglected at all studied potentials because the exclusion is damped by a coupled anion and free water transfer in the same direction. On the contrary, the rate of water expulsion out of exclusion effect $\left({ }^{K_{-\mathrm{H}_{2} \mathrm{O}^{\prime}}^{\prime}}\right)$ is a faster process of about $90 \mathrm{~s}^{-1}$ at all polarization potentials. In general, this rate is independent of the oxidation state of PEDOT.

The different rate between both transfers can be caused by the formation of two kinds of charge defects (polarons) previously observed in PEDOT [61] and derivative polymers[62,63]. On the one hand, the faster free water transfer can be related to highly mobile polarons delocalized on isolated polymer segments involving fast conformational movements of PEDOT backbone. On the other hand, the localized polarons should be because of $\mathrm{ClO}_{4}^{-}$insertion inside PEDOT, which fixes polarons on the PEDOT backbone.

\subsection{Mechanistic model}

From results, we suggest an electrochemical mechanism of PEDOT in aqueous solution considering the cube scheme of mechanism and species pathways of PEDOT proposed by Hillman et al. [24,25].

To simplify the discussion, we choose to explain the oxidation mechanism but it can be extrapolated to the reduction mechanism. In a first step, the removal of electrons in the molecular structure of PEDOT is the fastest process. Then, double bond formation shortens the distance between EDOT units decreasing the thickness of the film[64,65]. The free volume of the film is reduced involving a fast expulsion of free water molecules (eq (26)). As there is still anions transfer, this facilitates the transfer of free water (Figure 9). Dehydration step involves an increase of the dielectric constant of the film which could contribute to the pseudo-capacitive behavior of PEDOT[18,66]. 


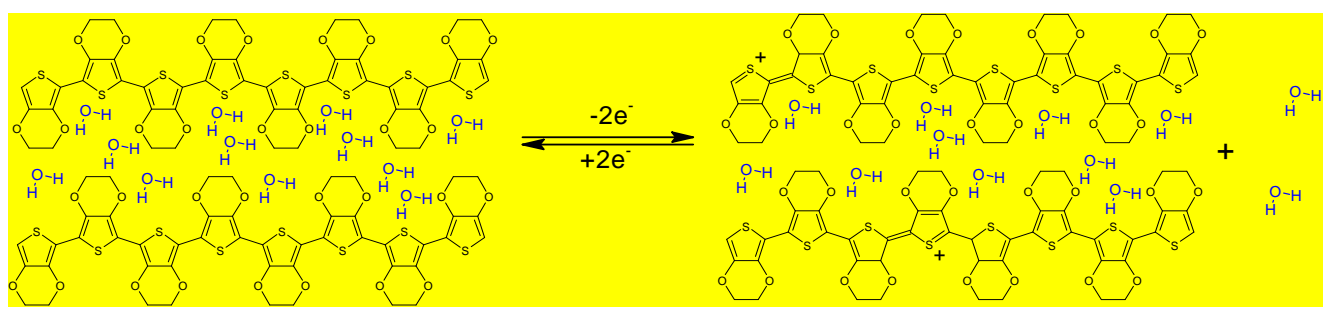

The resulting charge defects are compensated with the $\mathrm{ClO}_{-}^{-}$insertion increasing the polarity of PEDOT [48]. This fact involves a mechanical accommodation of charged polymeric chains and stored anions inside the PEDOT film by repulsive interactions (eq (27)). Possibly, conformational movements translated themselves as side-chain motions, which create free volume (swelling of the film). Simultaneously, this free volume is rapidly occupied by free water molecules from solution as the similar values of $K_{\mathrm{Cl0}}^{\prime \prime}$ and $K_{4 H_{3} O^{\prime}}^{\prime \prime}$ point out to.

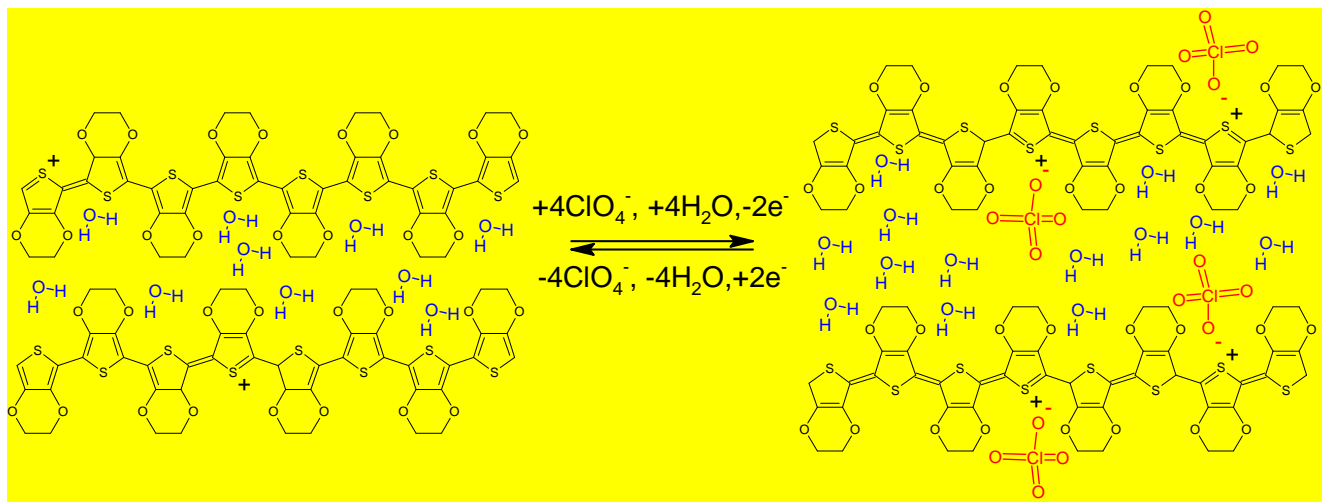

The here-proposed analysis of ac-electrogravimetry results and the mechanistic interpretation for PEDOT films can be used for further investigations on conducting polymers doped with immobile ions or ionomers like the PEDOT:Polystyrene sulfonate system [67-69].

\section{CONCLUSIONS}

This work is the first example of an ac-electrogravimetry study on the PEDOT films in $\mathrm{LiClO}_{4}$ aqueous solutions. The general equations to analyze the electrogravimetric response considering the exclusion effect are successfully applied. Mechanistic aspects in this p-type polymer prove to be more complicated than expected. Despite this, several interesting conclusions can complete the redox mechanism of PEDOT film in unprecedented detail.

Two different free water transfer processes were recognized and temporally separated by ac-electrogravimetry. The high electron conductivity of PEDOT allows faster molecular movements. The molecular reconfiguration may cause faster free water 
transfer before the anion transfer occurs. Film doping by anions involves a charge accommodation by repulsive interactions creating free volume. This fact favors the simultaneous free water insertion.

\section{ACKNOWLEDGMENTS}

Part of this work was supported by FEDER-CICyT project CTQ201128973/BQU.

\section{REFERENCES}

[1] B.L. Groenendaal, F. Jonas, D. Freitag, H. Pielartzik, J.R. Reynolds, Poly(3,4ethylenedioxythiophene) and its derivatives: Past, present, and future, Adv. Mater. 12 (2000) 481-494.

[2] S. Kirchmeyer, K. Reuter, Scientific importance, properties and growing applications of poly(3,4-ethylenedioxythiophene), J. Mater. Chem. 15 (2005) 2077-2088.

[3] Y. Wang, Research progress on a novel conductive polymer-poly $(3,4-$ ethylenedioxythiophene) (PEDOT), J. Phys. Conf. Ser. 152 (2009) 012023.

[4] M. Vazquez, J. Bobacka, M. Luostarinen, K. Rissanen, A. Lewenstam, A. Ivaska, Potentiometric sensors based on poly(3,4-ethylenedioxythiophene) (PEDOT) doped with sulfonated calix[4]arene and calix[4]resorcarenes, J. Solid State Electrochem. 9 (2005) 312-319.

[5] F. Jonas, J.T. Morrison, 3,4-polyethylenedioxythiophene (PEDT): Conductive coatings technical applications and properties, Synth. Met. 85 (1997) 1397-1398.

[6] T.M. Brown, J.S. Kim, R.H. Friend, F. Cacialli, R. Daik, W.J. Feast, Built-in field electroabsorption spectroscopy of polymer light-emitting diodes incorporating a doped poly(3,4-ethylene dioxythiophene) hole injection layer, Appl. Phys. Lett. 75 (1999) 1679-1681.

[7] J.-H. Huang, D. Kekuda, C.-W. Chu, K.-C. Ho, Electrochemical characterization of the solvent-enhanced conductivity of poly(3,4-ethylenedioxythiophene) and its application in polymer solar cells, J. Mater. Chem. 19 (2009) 3704-3712.

[8] G.A. Snook, P. Kao, A.S. Best, Conducting-polymer-based supercapacitor devices and electrodes, J. Power Sources. 196 (2011) 1-12.

[9] M.S. Cho, H.J. Seo, J.D. Nam, H.R. Choi, J.C. Koo, K.G. Song, Y. Lee, A solid state actuator based on the PEDOT/NBR system, Sens. Actuators B-Chem. 119 (2006) 621-624.

[10] D.-H. Kim, S.M. Richardson-Burns, J.L. Hendricks, C. Sequera, D.C. Martin, Effect of immobilized nerve growth factor on conductive polymers: Electrical properties and cellular response, Adv. Funct. Mater. 17 (2007) 79-86.

[11] L. Niu, C. Kvarnström, K. Fröberg, A. Ivaska, Electrochemically controlled surface morphology and crystallinity in poly(3,4-ethylenedioxythiophene) films, Synth. Met. 122 (2001) 425-429.

[12] E. Poverenov, M. Li, A. Bitler, M. Bendikov, Major Effect of Electropolymerization Solvent on Morphology and Electrochromic Properties of PEDOT Films, Chem. Mater. 22 (2010) 4019-4025.

[13] T.F. Otero, J.G. Martinez, Artificial Muscles: A Tool To Quantify Exchanged Solvent during Biomimetic Reactions, Chem. Mater. 24 (2012) 4093-4099. 
[14] A. Bund, R. Peipmann, Application of PEDOT layers for the electrogravimetric detection of sulphate and phosphate in aqueous media, Electrochimica Acta. 53 (2008) 3772-3778.

[15] M.J. Brown, A.R. Hillman, S.J. Martin, R.W. Cernosek, H.L. Bandey, Manipulation of electroactive polymer film viscoelasticity: the roles of applied potential and frequency, J. Mater. Chem. 10 (2000) 115-126.

[16] E. Kriván, C. Visy, J. Kankare, Deprotonation and Dehydration of Pristine PPy/DS Films during Open-Circuit Relaxation: an Ignored Factor in Determining the Properties of Conducting Polymers, J. Phys. Chem. B. 107 (2003) 1302-1308.

[17] A. Bund, S. Neudeck, Effect of the solvent and the anion on the doping/dedoping behavior of poly(3,4-ethylenedioxythiophene) films studied with the electrochemical quartz microbalance, J. Phys. Chem. B. 108 (2004) 17845-17850.

[18] W. Plieth, A. Bund, U. Rammelt, S. Neudeck, L.M. Duc, The role of ion and solvent transport during the redox process of conducting polymers, Electrochimica Acta. 51 (2006) 2366-2372.

[19] A.R. Hillman, I. Efimov, K.S. Ryder, Time-Scale- and Temperature-Dependent Mechanical Properties of Viscoelastic Poly(3,4-ethylenedioxythiophene) Films, J. Am. Chem. Soc. 127 (2005) 16611-16620.

[20] S. Bruckenstein, A. Hillman, Consequences of Thermodynamic Restraints on Solvent and Ion Transfer During Redox Switching of Electroactive Polymers, J. Phys. Chem. 92 (1988) 4837-4839.

[21] S. Bruckenstein, A. Hillman, Solvent and Salt Transfer Upon Redox Switching of Electroactive Polymers, J. Phys. Chem. 95 (1991) 10748-10752.

[22] A.R. Hillman, S.J. Daisley, S. Bruckenstein, Solvent effects on the electrochemical p-doping of PEDOT, Phys. Chem. Chem. Phys. 9 (2007) 2379-2388.

[23] A.R. Hillman, S.J. Daisley, S. Bruckenstein, Kinetics and mechanism of the electrochemical p-doping of PEDOT, Electrochem. Commun. 9 (2007) 13161322.

[24] A. Hillman, S. Bruckenstein, Role of Film History and Observational Timescale on Redox Switching Kinetics of Electroactive Films .1. a New Model for Permselective Films with Polymer Relaxation Processes, J. Chem. Soc.-Faraday Trans. 89 (1993) 339-348.

[25] A.R. Hillman, S. Bruckenstein, Role of film history and observational timescale in redox switching kinetics of electroactive films. Part 2.-Visualizing electrochemical redox switching pathways involving four or more distinct relaxation times, J. Chem. Soc. Faraday Trans. 89 (1993) 3779-3782.

[26] R. Hass, J. García-Cañadas, G. García-Belmonte, Electrochemical impedance analysis of the redox switching hysteresis of poly(3,4-ethylenedioxythiophene) films, J. Electroanal. Chem. 577 (2005) 99-105.

[27] J. Agrisuelas, C. Gabrielli, J.J. Garcia-Jareño, H. Perrot, F. Vicente, Ionic and Free Solvent Motion in Poly(azure A) Studied by ac-Electrogravimetry, J. Phys. Chem. C. 115 (2011) 11132-11139.

[28] J. Agrisuelas, C. Gabrielli, J.J. García-Jareño, H. Perrot, F. Vicente, Kinetic and Mechanistic Aspects of a Poly(o-Toluidine)-Modified Gold Electrode. 2. Alternating Current Electrogravimetry Study in H2SO4 Solutions, J. Phys. Chem. C. 116 (2012) 15630-15640.

[29] J. Agrisuelas, C. Gabrielli, J.J. García-Jareño, H. Perrot, F. Vicente, Effects of anion size on the electrochemical behavior of $\mathrm{H} 2 \mathrm{SO} 4$-structured poly(o-toluidine) 
films. An ac-electrogravimetry study in acid solutions, Electrochimica Acta. 132 (2014) 561-573.

[30] J. Agrisuelas, C. Gabrielli, J.J. Garcia-Jareño, H. Perrot, O. Sel, F. Vicente, Polymer dynamics in thin p-type conducting films investigated by acelectrogravimetry. Kinetics aspects on anion exclusion, free solvent transfer, and conformational changes in poly(o-toluidine), Electrochimica Acta. (2014) accepted.

[31] T.F. Otero, J.G. Martinez, Biomimetic intracellular matrix (ICM) materials, properties and functions. Full integration of actuators and sensors, J. Mater. Chem. B. 1 (2013) 26-38.

[32] T.F. Otero, J.G. Martinez, Structural and Biomimetic Chemical Kinetics: Kinetic Magnitudes Include Structural Information, Adv. Funct. Mater. 23 (2013) 404416.

[33] C. Gabrielli, J.J. García-Jareño, M. Keddam, H. Perrot, F. Vicente, AcElectrogravimetry Study of Electroactive Thin Films. I. Application to Prussian Blue, J. Phys. Chem. B. 106 (2002) 3182-3191.

[34] C. Gabrielli, J.J. Garcia-Jareño, M. Keddam, H. Perrot, F. Vicente, AcElectrogravimetry Study of Electroactive Thin Films. II. Application to Polypyrrole, J. Phys. Chem. B. 106 (2002) 3192-3201.

[35] C. Gabrielli, J. Garcia-Jareño, H. Perrot, Charge transport in electroactive thin films investigated by ac electrogravimetry, ACH-Models Chem. 137 (2000) 269297.

[36] J. Agrisuelas, J.J. Garcia-Jareño, D. Gimenez-Romero, F. Vicente, Innovative Combination of Three Alternating Current Relaxation Techniques: Electrical Charge, Mass, and Color Impedance Spectroscopy. Part I: The Tool, J. Phys. Chem. C. 113 (2009) 8430-8437.

[37] J. Agrisuelas, J. Juan Garcia-Jareño, D. Gimenez-Romero, F. Vicente, Innovative Combination of Three Alternating Current Relaxation Techniques: Electrical Charge, Mass, and Color Impedance Spectroscopy. Part II: Prussian Blue reversible arrow Everitt's Salt Process, J. Phys. Chem. C. 113 (2009) 8438-8446.

[38] L.T.T. Kim, C. Gabrielli, A. Pailleret, H. Perrot, Correlation between ion-exchange properties and swelling/shrinking processes in hexasulfonated calix[6]arene doped polypyrrole films: ac-electrogravimetry and electrochemical atomic force microscopy investigations, Electrochimica Acta. 56 (2011) 3516-3525.

[39] L.T.T. Kim, C. Gabrielli, A. Pailleret, H. Perrot, Ions/Solvent Exchanges and Electromechanical Processes in Hexasulfonated Calix[6]Arene Doped Polypyrrole Films: Towards a Relaxation Mechanism, Electrochem. Solid State Lett. 14 (2011) F9-F11.

[40] L. Lizarraga, E.M. Andrade, M.I. Florit, F.V. Molina, Quasi-Equilibrium Volume Changes of Polyaniline Films upon Redox Switching. Formal Potential Distribution and Configurational Modeling, J. Phys. Chem. B. 109 (2005) 1881518821.

[41] K. Kaneto, M. Kaneko, Contribution of conformational change of polymer structure to electrochemomechanical deformation based on polyaniline, Appl. Biochem. Biotechnol. 96 (2001) 13-23.

[42] B. Zanfrognini, A. Colina, A. Heras, C. Zanardi, R. Seeber, J. López-Palacios, A UV-Visible/Raman spectroelectrochemical study of the stability of poly(3,4ethylendioxythiophene) films, Polym. Degrad. Stab. 96 (2011) 2112-2119.

[43] J.R. Macdonald, Comparison and application of two methods for the least squares analysis of immittance data, Solid State Ion. 58 (1992) 97-107. 
[44] D. Benito, C. Gabrielli, J.J. García-Jareño, M. Keddam, H. Perrot, F. Vicente, Study by EQCM on the voltammetric electrogeneration of poly(neutral red). The effect of the $\mathrm{pH}$ and the nature of cations and anions on the electrochemistry of the films, Electrochimica Acta. 48 (2003) 4039-4048.

[45] T.-Y. Chiang, M.-C. Huang, C.-H. Tsai, The effects of solvent on the electrochromic properties of poly(3,4-ethylenedioxythiophene), Rsc Adv. 4 (2014) 21201-21207.

[46] H. Grande, T.F. Otero, Conformational movements explain logarithmic relaxation in conducting polymers, Electrochimica Acta. 44 (1999) 1893-1900.

[47] I. Efimov, S. Winkels, J.W. Schultze, EQCM study of electropolymerization and redox cycling of 3,4-polyethylenedioxythiophene, J. Electroanal. Chem. 499 (2001) 169-175.

[48] X. Chen, K.-Z. Xing, O. Inganäs, Electrochemically Induced Volume Changes in Poly(3,4-ethylenedioxythiophene), Chem. Mater. 8 (1996) 2439-2443.

[49] S.N. Eliseeva, T.A. Babkova, V.V. Kondratiev, Mass transfer of ions and solvent at redox processes in poly-3,4-ethylenedioxythiophene films, Russ. J. Electrochem. 45 (2009) 152-159.

[50] C. Lei, P. Wilson, C. Lekakou, Effect of poly(3,4-ethylenedioxythiophene) (PEDOT) in carbon-based composite electrodes for electrochemical supercapacitors, J. Power Sources. 196 (2011) 7823-7827.

[51] J. Agrisuelas, D. Giménez-Romero, J.J. García-Jareño, F. Vicente, Vis/NIR spectroelectrochemical analysis of poly-(Azure A) on ITO electrode, Electrochem. Commun. 8 (2006) 549-553.

[52] J.G. Martinez, T.F. Otero, E.W.H. Jager, Effect of the Electrolyte Concentration and Substrate on Conducting Polymer Actuators, Langmuir. 30 (2014) 3894-3904.

[53] C. Gabrielli, H. Takenouti, O. Haas, A. Tsukada, Impedance Investigation of the Charge Transport in Film-Modified Electrodes, J. Electroanal. Chem. 302 (1991) 59-89.

[54] M. Mathias, O. Haas, An Alternating-Current Impedance Model Including Migration and Redox-Site Interactions at Polymer-Modified Electrodes, J. Phys. Chem. 96 (1992) 3174-3182.

[55] W.J. Doherty, R.J. Wysocki, N.R. Armstrong, S.S. Saavedra, Potential-modulated, attenuated total reflectance spectroscopy of poly(3,4-ethylenedioxythiophene) and poly(3,4-ethylenedioxythiophene methanol) copolymer films on indium-tin oxide, J. Phys. Chem. B. 110 (2006) 4900-4907.

[56] C. Gabrielli, M. Keddam, N. Nadi, H. Perrot, Ions and solvent transport across conducting polymers investigated by ac electrogravimetry. Application to polyaniline, J. Electroanal. Chem. 485 (2000) 101-113.

[57] J. Agrisuelas, J.J. García-Jareño, D. Gimenez-Romero, F. Vicente, An approach to the electrochemical activity of poly-(phenothiazines) by complementary electrochemical impedance spectroscopy and Vis-NIR spectroscopy, Electrochimica Acta. 55 (2010) 6128-6135.

[58] A. Zykwinska, W. Domagala, M. Lapkowski, ESR spectroelectrochemistry of poly(3,4-ethylenedioxythiophene) (PEDOT), Electrochem. Commun. 5 (2003) 603-608.

[59] D. Benito, C. Gabrielli, J.J. García-Jareño, M. Keddam, H. Perrot, F. Vicente, An electrochemical impedance and ac-electrogravimetry study of PNR films in aqueous salt media, Electrochem. Commun. 4 (2002) 613-619. 
[60] J. Agrisuelas, C. Gabrielli, J.J. Garcia-Jareño, D. Gimenez-Romero, J. Gregori, H. Perrot, F. Vicente, Usefulness of $\mathrm{F}(\mathrm{dm} / \mathrm{dQ})$ function for elucidating the ions role in PB films, J. Electrochem. Soc. 154 (2007) F134-F140.

[61] A. Zykwinska, W. Domagala, A. Czardybon, B. Pilawa, M. Lapkowski, In situ EPR spectroelectrochemical studies of paramagnetic centres in poly $(3,4-$ ethylenedioxythiophene) (PEDOT) and poly(3,4-butylenedioxythiophene) (PBuDOT) films, Chem. Phys. 292 (2003) 31-45.

[62] C. Visy, J. Kankare, Polythiophene puzzle - a plausible solution, J. Electroanal. Chem. 442 (1998) 175-188.

[63] C. Visy, J. Kankare, Direct in situ conductance evidence for non-faradaic electrical processes in poly(3-methylthiophene), Electrochimica Acta. 45 (2000) 1811-1820.

[64] E.-G. Kim, J.-L. Bredas, Electronic Evolution of Poly(3,4ethylenedioxythiophene) (PEDOT): From the Isolated Chain to the Pristine and Heavily Doped Crystals, J. Am. Chem. Soc. 130 (2008) 16880-16889.

[65] J. Roncali, Conjugated Poly(thiophenes) - Synthesis, Functionalization, and Applications, Chem. Rev. 92 (1992) 711-738.

[66] E. Kriván, C. Visy, J. Kankare, Key role of the desolvation in the achievement of the quasi-metallic state of electronically conducting polymers, Electrochimica Acta. 50 (2005) 1247-1254.

[67] W. Hong, Y. Xu, G. Lu, C. Li, G. Shi, Transparent graphene/PEDOT-PSS composite films as counter electrodes of dye-sensitized solar cells, Electrochem. Commun. 10 (2008) 1555-1558.

[68] S.K.M. Jonsson, J. Birgerson, X. Crispin, G. Greczynski, W. Osikowicz, A.W.D. van der Gon, W.R. Salaneck, M. Fahlman, The effects of solvents on the morphology and sheet resistance in poly (3,4-ethylenedioxythiophene)polystyrenesulfonic acid (PEDOT-PSS) films, Synth. Met. 139 (2003) 1-10.

[69] G. Greczynski, T. Kugler, M. Keil, W. Osikowicz, M. Fahlman, W.R. Salaneck, Photoelectron spectroscopy of thin films of PEDOT-PSS conjugated polymer blend: a mini-review and some new results, J. Electron Spectrosc. Relat. Phenom. 121 (2001) 1-17. 


\section{TABLES}

Table 1. Number of water molecules excluded by anion transfer $\left(\mathrm{H}_{2} \mathbb{Q}\right), n$, number of transferred water molecules owing to conformational changes $\left(\mathrm{H}_{2} \mathrm{O}^{3}\right)$ in the opposite direction of anions, $n^{*}$, calculated from eq (21) and number of transferred water molecules owing to conformational changes in the same direction of anions, $n^{p^{*}}$, calculated from eq (22). The evolution of net water molecules transferred during the electrochemical reaction of PEDOT film was calculated as $n^{\prime \prime}-n^{*}-n$.

\begin{tabular}{lccccccc}
\hline$E / \mathrm{V}$ & $n^{n}$ & $n^{n^{*}}$ & net & $\begin{array}{c}E / \\
\mathrm{V}\end{array}$ & $n^{*}$ & $n^{n^{*}}$ & net \\
\hline-0.25 & 5.7 & 8.5 & -1.9 & 0.25 & 11.1 & 17.8 & 2.0 \\
-0.2 & 5.3 & 8.5 & -1.5 & 0.3 & 20.1 & 27.2 & 2.4 \\
-0.15 & 8.3 & 12.0 & -1.0 & 0.35 & 13.0 & 20.6 & 2.9 \\
-0.1 & 9.4 & 13.3 & -0.8 & 0.4 & 22.4 & 30.4 & 3.3 \\
-0.05 & 8.9 & 13.2 & -0.4 & 0.45 & 18.5 & 26.5 & 3.3 \\
0 & 7.7 & 12.2 & -0.2 & 0.5 & 18.3 & 26.7 & 3.7 \\
0.05 & 15.5 & 20.5 & 0.3 & 0.55 & 18.1 & 26.7 & 3.9 \\
0.1 & 10.6 & 16.0 & 0.7 & 0.6 & 28.6 & 36.6 & 3.3 \\
0.15 & 13.3 & 19.1 & 1.1 & 0.65 & 50.0 & 58.2 & 3.5 \\
0.2 & 18.7 & 24.9 & 1.5 & 0.7 & 51.2 & 59.3 & 3.4 \\
\hline
\end{tabular}




\section{FIGURES CAPTIONS}

Figure 1. Electrode|film|solution cross-section of a rigid polymer showing the exclusion effect caused between anions $\left(\mathrm{A}^{-}\right)$and free water molecules $\left(\mathrm{H}_{2} \mathrm{O}\right), k_{\mathrm{A}^{-}}^{*}$ and $k_{\mathrm{H}_{2} \mathrm{O}}^{*}$ are the kinetic constants of anion and free water insertion to polymer, respectively. $k_{A_{4}-}$ and $k_{\mathrm{H}_{2} \mathrm{O}}$ are the kinetic constants of anion and free water expulsion from polymer, respectively. $d_{f}$ is the polymer film thickness and the circles represent the molecule volume.

Figure 2. Selected cyclic voltammograms of PEDOT electrogeneration in $0.1 \mathrm{M} \mathrm{LiClO}_{4}$ and $0.05 \mathrm{M}$ PEDOT in acetonitrile between $-0.2 \mathrm{~V}$ and $1.2 \mathrm{~V}$. Scan rate is $100 \mathrm{mV} \mathrm{s}^{-1}$. Inset is the increment of the mass after each cycle. The solid line is a guide-to-the eye.

Figure 3. Tenth cyclic voltammogram and corresponding time differential of the mass (a) and instantaneous molar mass calculated as $\mathrm{Fdm} / \mathrm{dq}$ of PEDOT electrogeneration in $0.1 \mathrm{M} \mathrm{LiClO}_{4}$ and $0.05 \mathrm{M}$ PEDOT in acetonitrile between $-0.2 \mathrm{~V}$ and $1.2 \mathrm{~V}$. Scan rate $100 \mathrm{mV} \mathrm{s}^{-1}$. Dashed line in (b) indicates the molar mass of $\mathrm{ClO}_{-}^{-}\left(\mathrm{M}_{\mathrm{ClO}}^{-}\right)$as a reference. Open circles and solid circles represent the oxidation direction the reduction direction, respectively.

Figure 4. Representative cyclic voltammogram and corresponding time differential of the mass (a) and instantaneous molar mass calculated as $\mathrm{Fdm} / \mathrm{d}$ of a thin PEDOT film in $0.1 \mathrm{M} \mathrm{LiClO}_{4}$ aqueous solution between $-0.4 \mathrm{~V}$ and $0.8 \mathrm{~V}$. Scan rate $100 \mathrm{mV} \mathrm{s}^{-1}$. Dashed line in (b) indicates the molar mass of $\mathrm{ClO}_{4}^{-}\left({ }^{M \sigma_{4}^{-}}\right)$as a reference. Open circles and solid circles represent the oxidation direction the reduction direction, respectively.

Figure 5. Experimental (symbols) and theoretical (lines) charge/potential transfer function, $\Delta q / \Delta E(w)$ of a thin PEDOT film in $0.1 \mathrm{M} \mathrm{LiClO}_{4}$ aqueous solution at $-0.25 \mathrm{~V}$ (a) and $0.5 \mathrm{~V}$ (b). Inset is a cyclic voltammetry of thin PEDOT film in $0.1 \mathrm{M} \mathrm{LiClO}_{4}$ aqueous solution between $-0.4 \mathrm{~V}$ and $0.8 \mathrm{~V}$. Scan rate $100 \mathrm{mV} \mathrm{s}^{-1}$. 
Figure 6. Real part of mass/charge transfer function at low frequency domain, $(R \in(F \Delta m) / \Delta q)$, of a thin PEDOT film in $0.1 \mathrm{M} \mathrm{LiClO}_{4}$ aqueous solution at different potential perturbations.

Figure 7. Experimental (symbols) and theoretical (lines) mass/potential transfer function, $\stackrel{\Delta m}{\Delta} / \Delta E(\omega)$ of a thin PEDOT film in $0.1 \mathrm{M} \mathrm{LiClO}_{4}$ aqueous solution at -0.25 $\mathrm{V}$ (a) and $0.5 \mathrm{~V}(\mathrm{~b})$. Inset is a cyclic voltammetry of thin PEDOT film in $0.1 \mathrm{M} \mathrm{LiClO}_{4}$ aqueous solution between $-0.4 \mathrm{~V}$ and $0.8 \mathrm{~V}$. Scan rate $100 \mathrm{mV} \mathrm{s}^{-1}$.

Figure 8. Evolution of the derivative of the insertion law of $\mathrm{ClO}_{4}^{-},{ }^{d} \Gamma_{\mathrm{ClO}}^{-} / d E$, at different polarization potentials of a thin PEDOT film in $0.1 \mathrm{M} \mathrm{LiClO}_{4}$ aqueous solution. Solid line is the simulation of eq (20) using the reached parameters by fitting of experimental results. The fitting parameters are included inside the plot.

Figure 9. $G_{-\mathrm{H}_{2} \mathrm{O}^{\prime}}, G_{+\mathrm{H}_{2} \mathrm{O}^{\prime}}$ and ${ }^{G_{\mathrm{ClO}}^{-}}$evolution with respect to potentials perturbation obtained by fitting $\Delta q / \Delta E(\omega)$ and $\frac{\Delta m}{\Delta E(\omega)}$ with the theoretical functions of a thin PEDOT film in $0.1 \mathrm{M} \mathrm{LiClO}_{4}$ aqueous solution.

Figure 10. ${ }^{\mathrm{H}_{2} \mathrm{O}^{\prime}}, \mathbb{K}_{+\mathrm{H}_{2} \mathrm{O}^{\prime}}^{\prime}$ and $K_{\mathrm{Cl} 0_{4}^{-}}^{v}$ evolution at different polarization potentials obtained by fitting $\Delta q / \Delta E(\omega)$ and $\Delta m / \Delta E(\omega)$ with the theoretical functions of a thin PEDOT film in $0.1 \mathrm{M} \mathrm{LiClO}_{4}$ aqueous solution. 


\section{FIGURES}

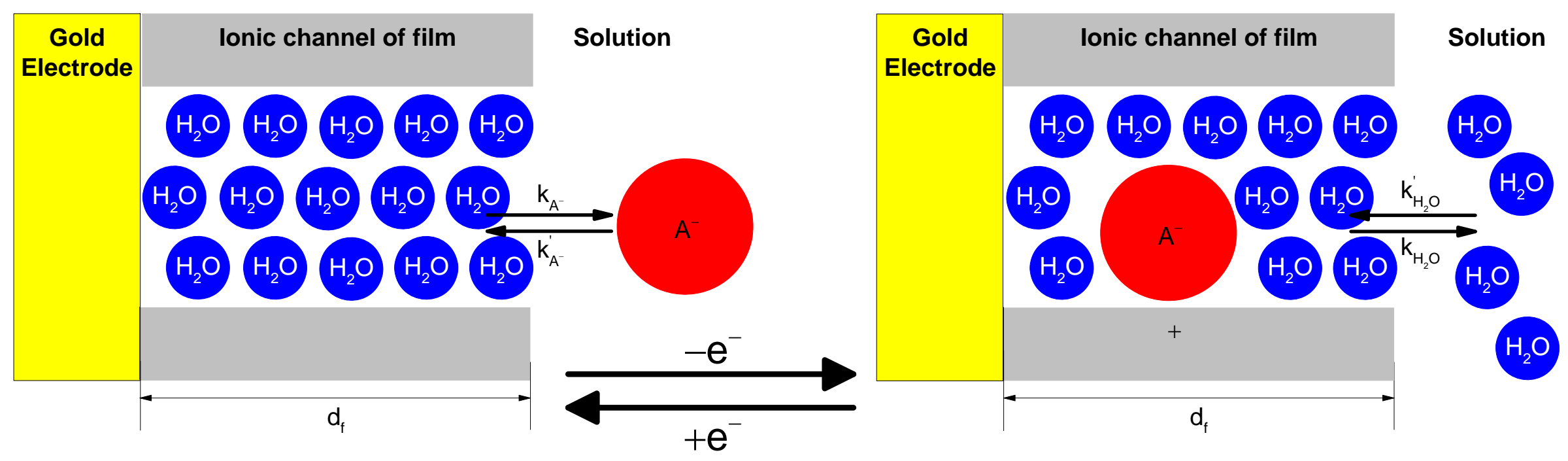

Figure 


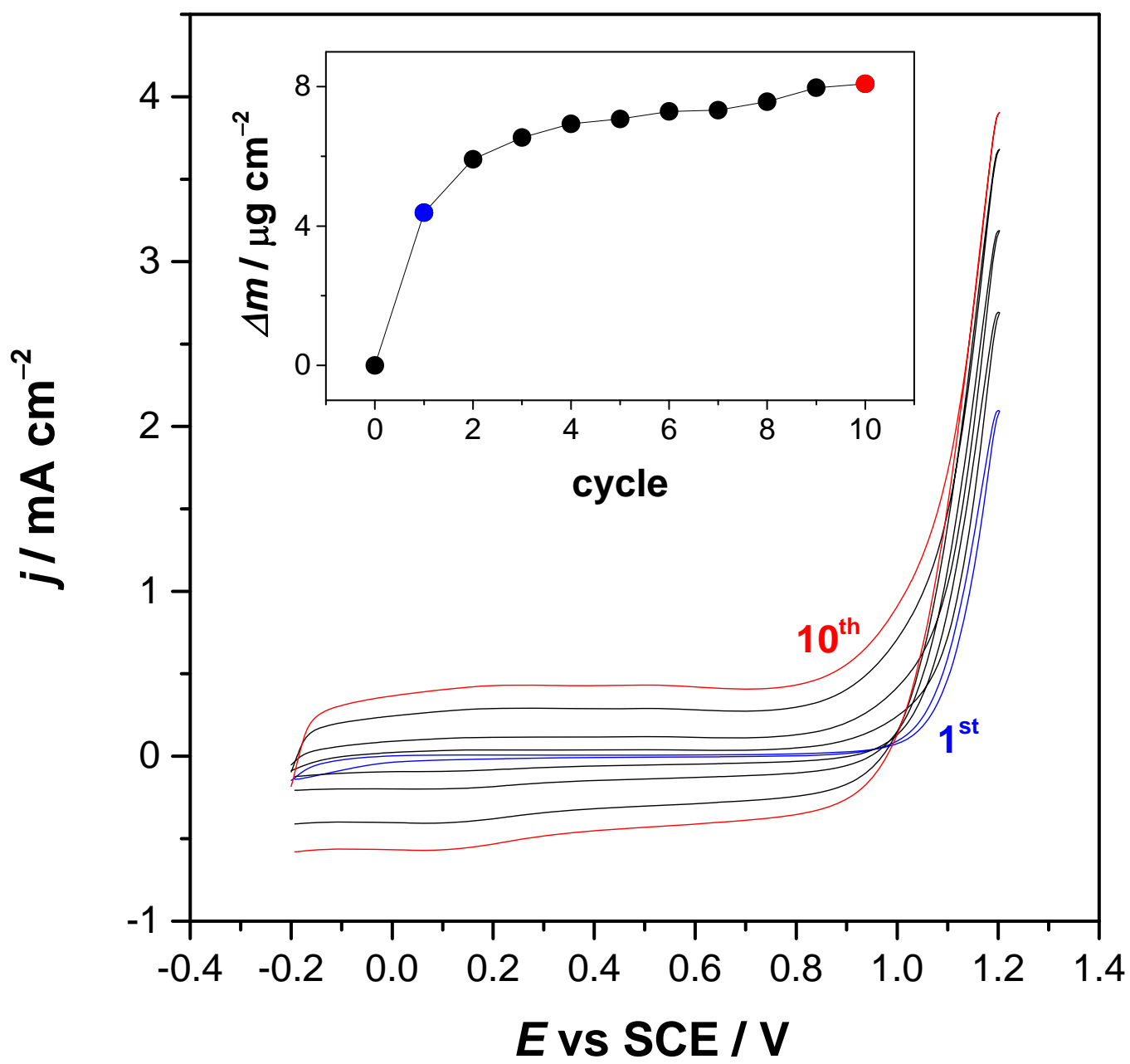

Figure 


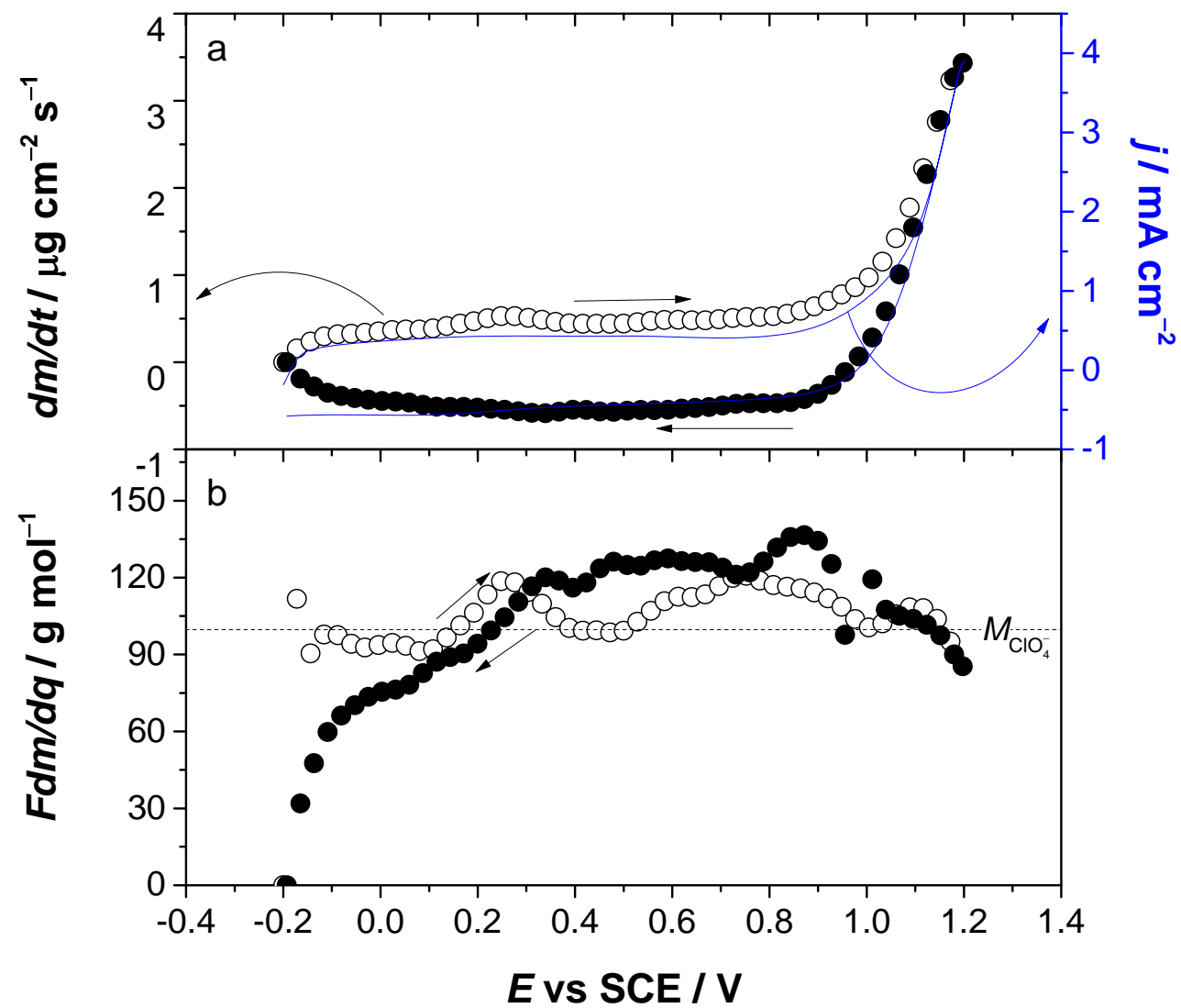

Figure 


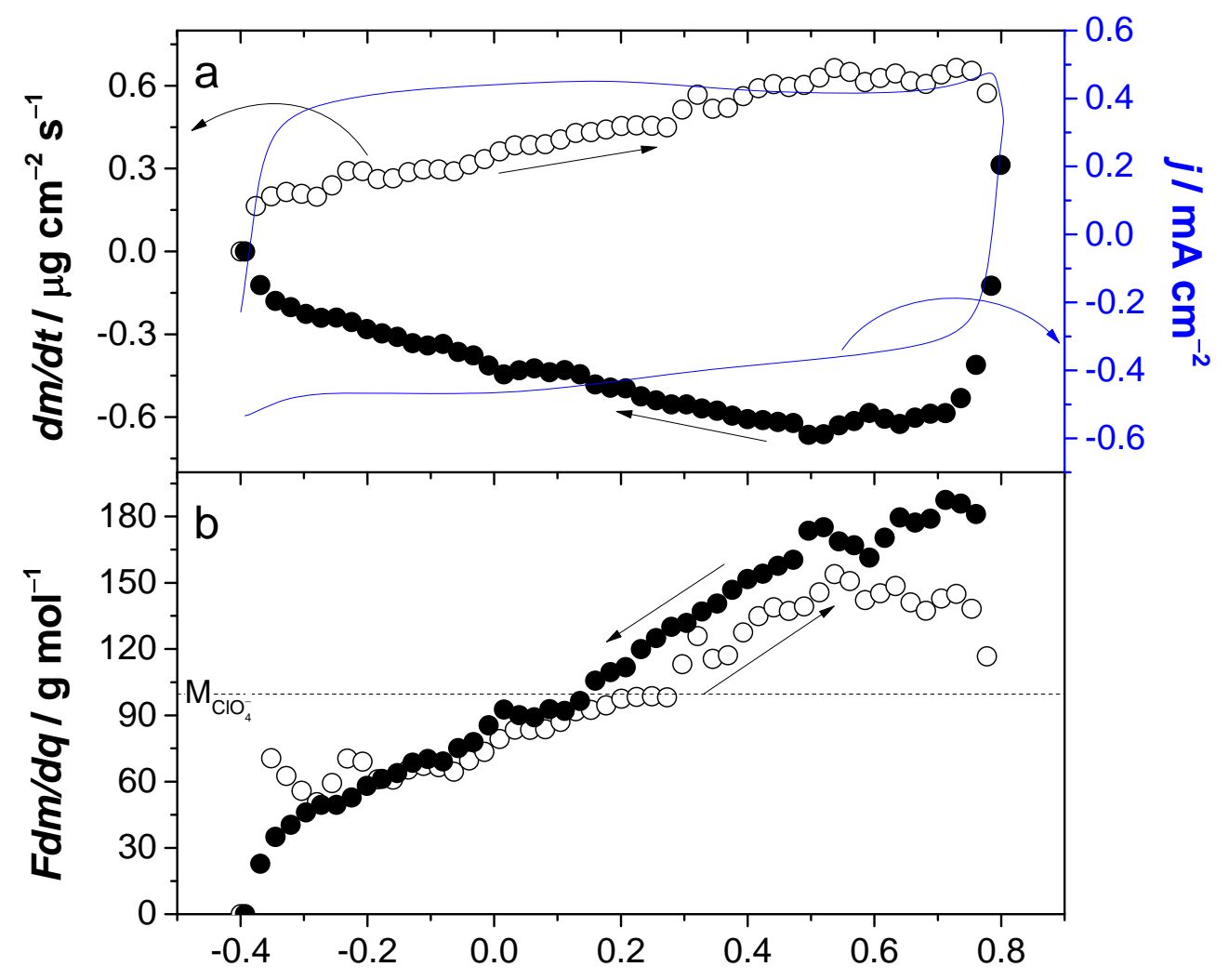

E vs SCE I V

Figure 


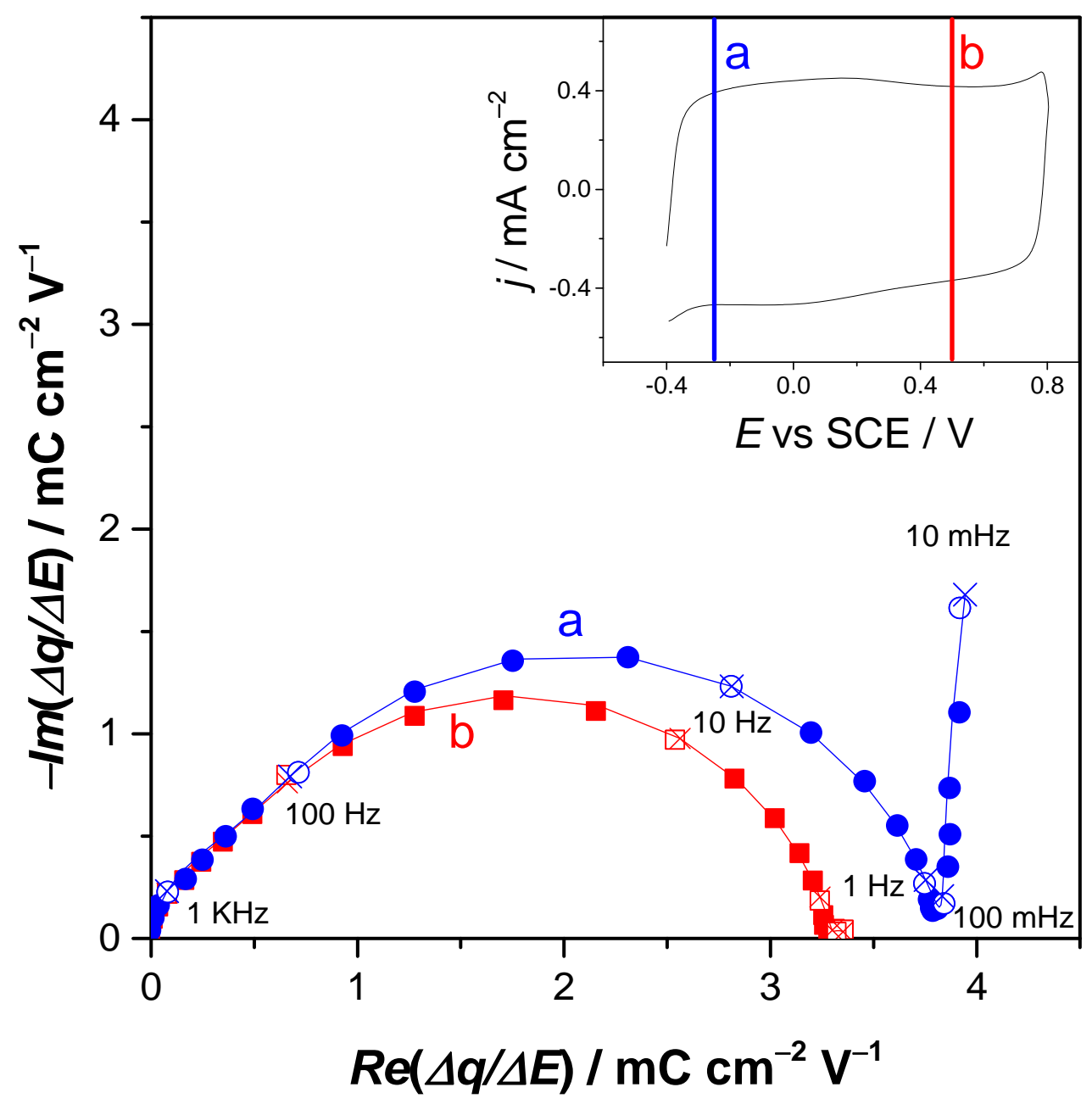

Figure 


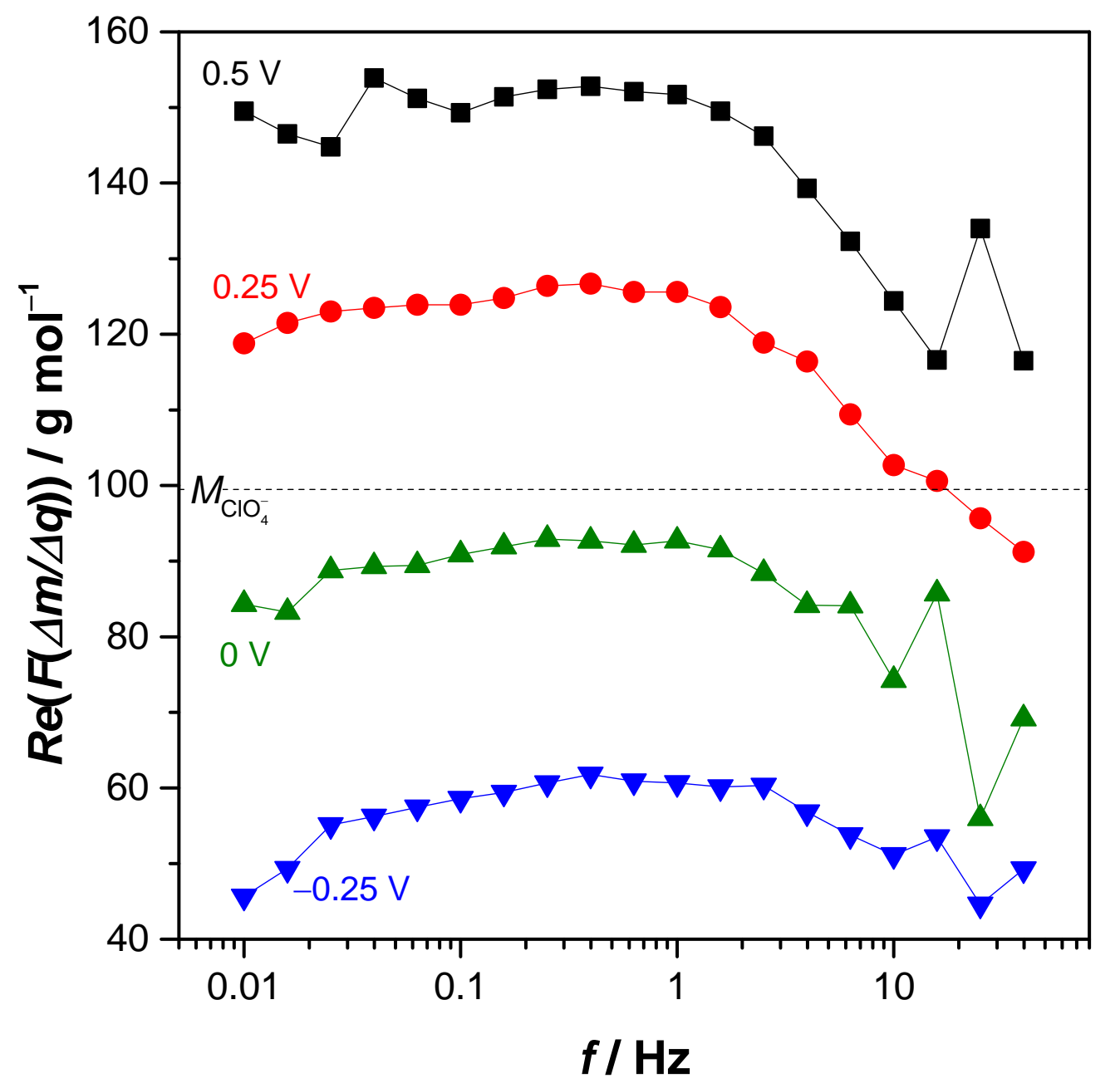

Figure 


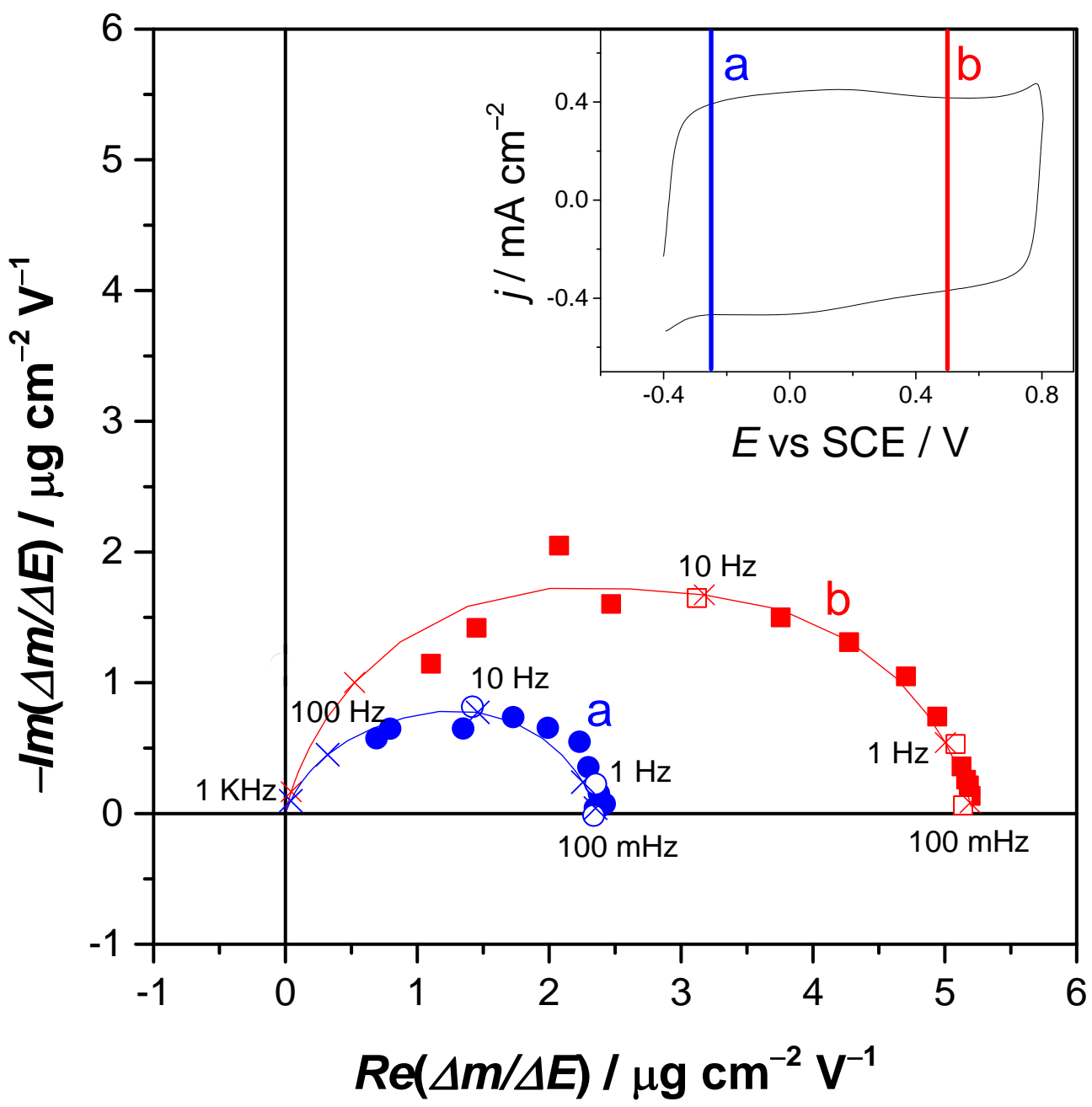

Figure 


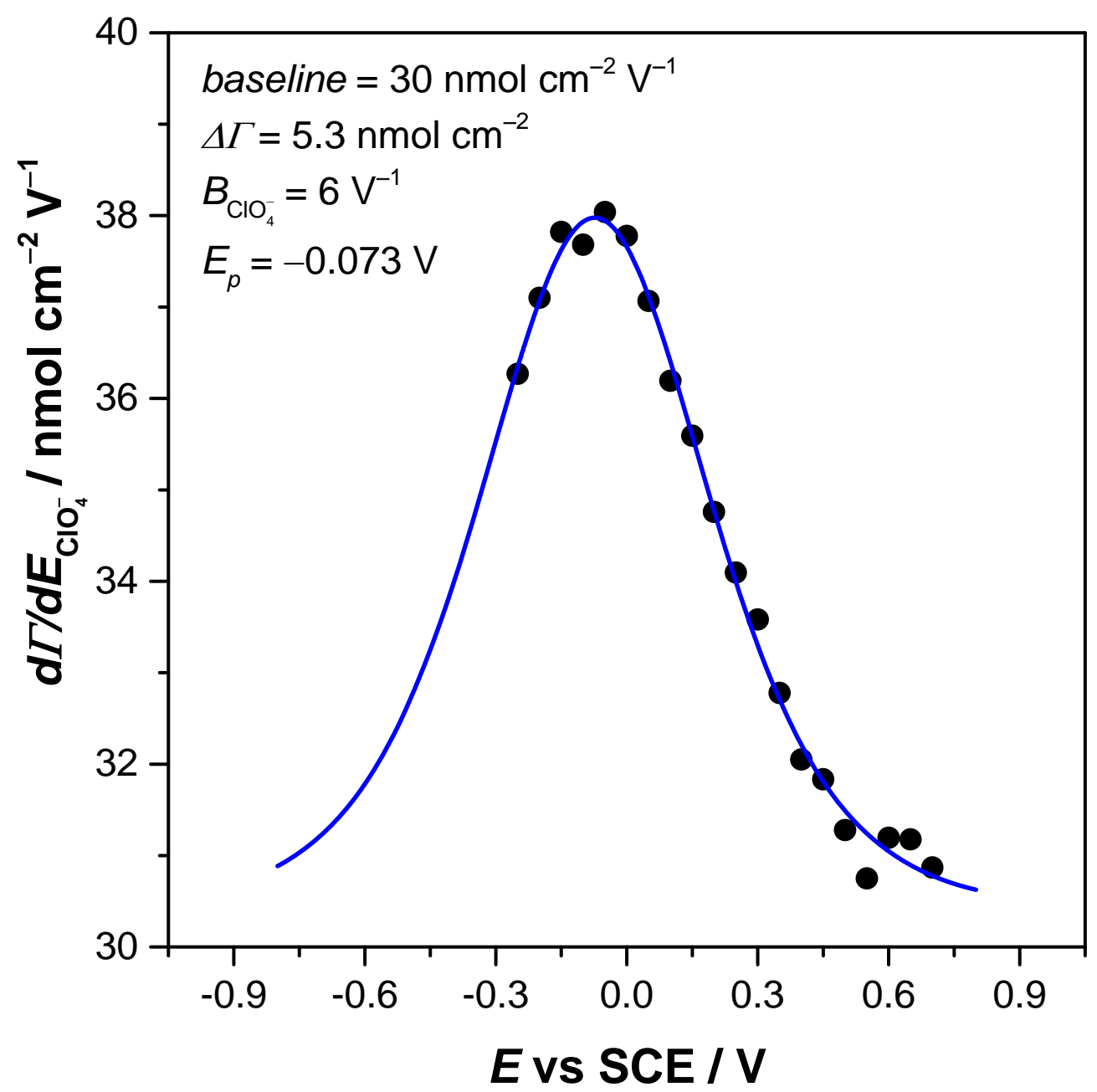

Figure 


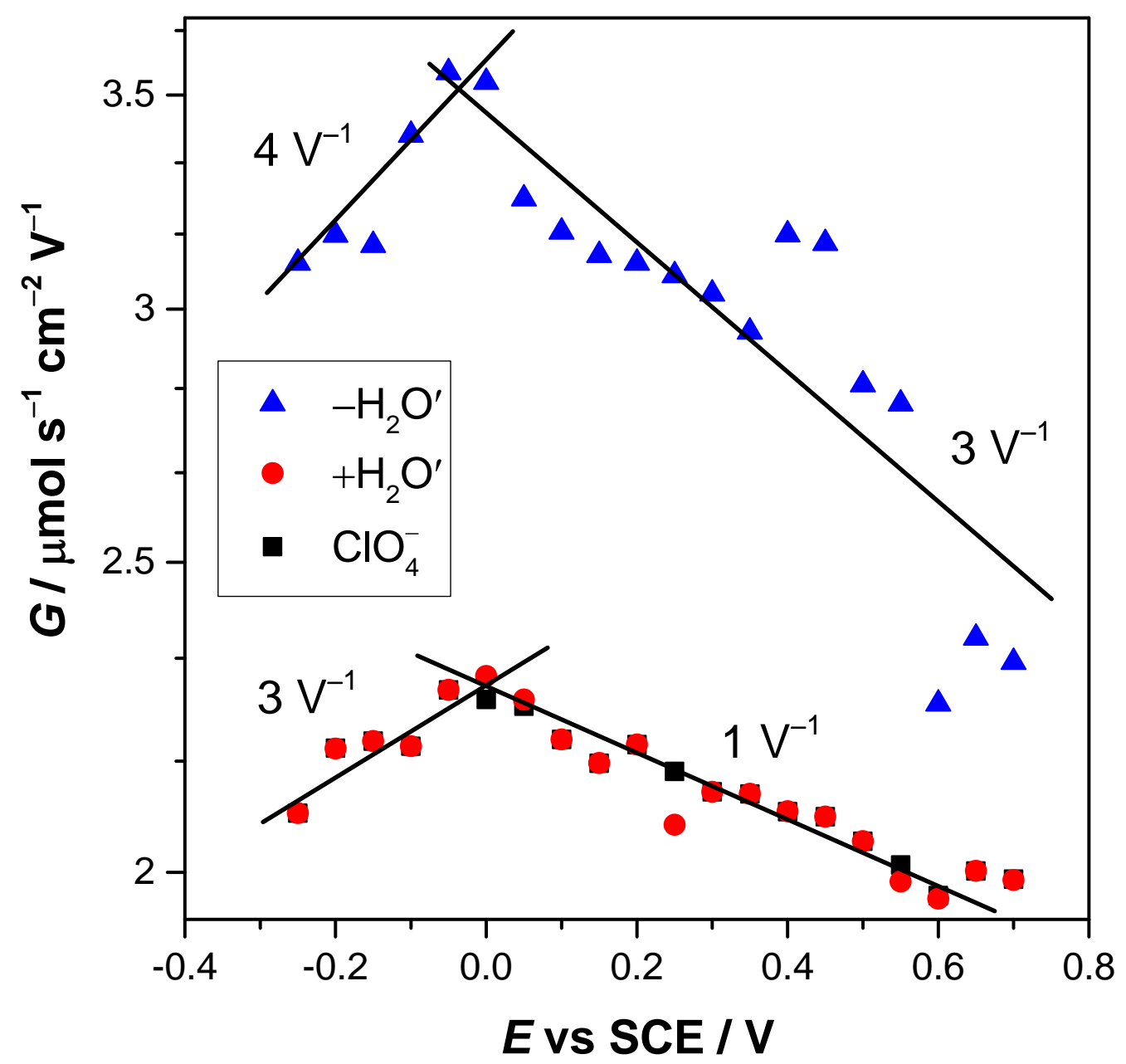

Figure 


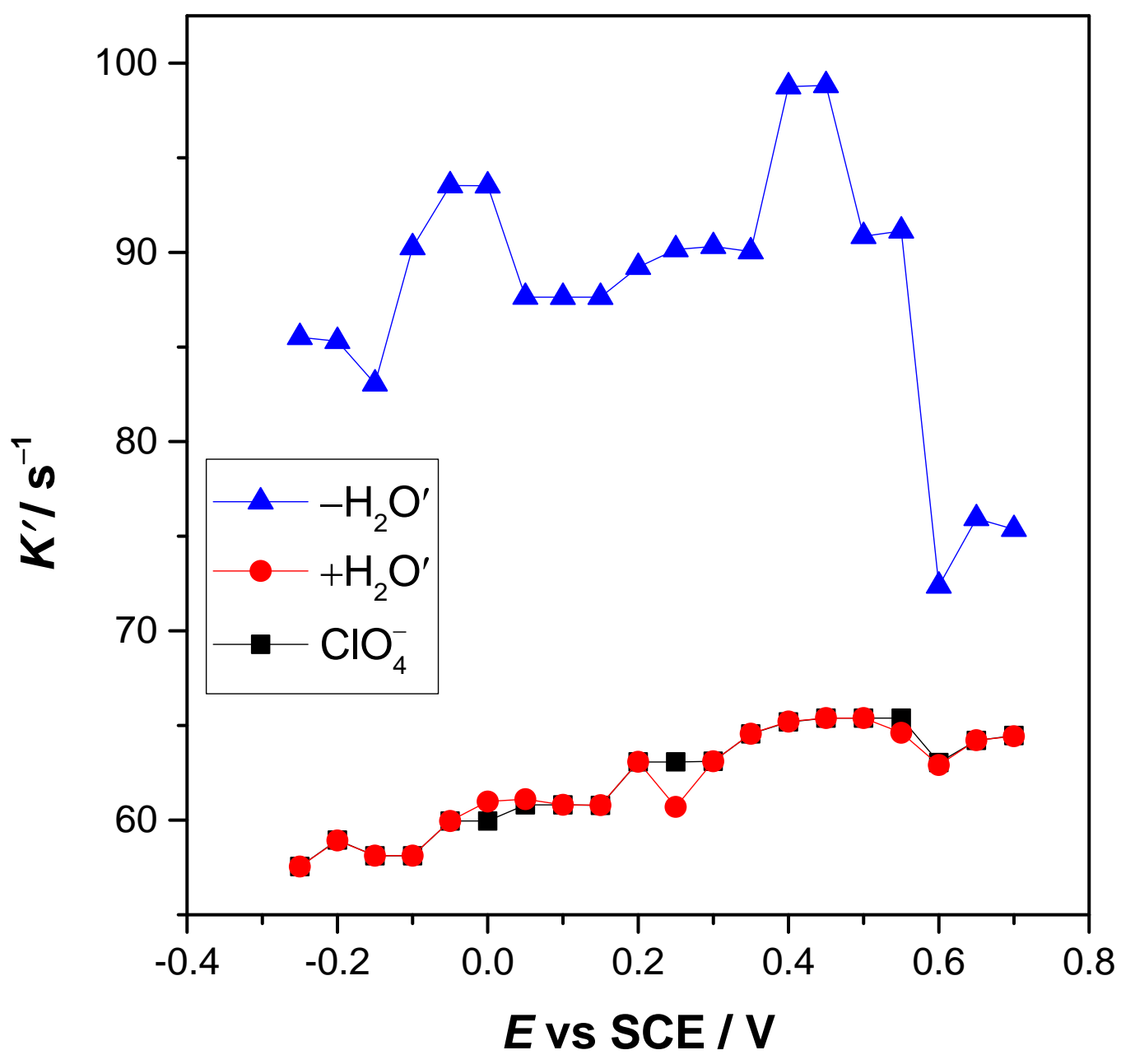

Figure 10 